\title{
EL VIAJE DE ESPAÑA DEL MARQUÉS DE VALDEFLORES. UN INTENTO FALLIDO DE CATALOGACIÓN DE LOS MONUMENTOS Y ANTIGÜEDADES DE ESPAÑA
}

\section{THE JOURNEY OF SPAIN'S MARQUÉS DE VALDEFLORES. A FAILED ATTEMPT TO CATALOG THE MONUMENTS AND ANTIQUITIES OF SPAIN}

\author{
JESÚS SALAS ÁLVAREZ*
}

Resumen: El viaje de España de Luis José Velázquez de Velasco fue el primer intento de catalogar las antigüedades de la nación, para su posterior utilización en una nueva Historia de España. Impulsado por la Corona, que puso a su disposición el aparato administrativo, para utilizar posteriormente la documentación conseguida en la cuestión del Patronato Regio frente al Papado. Se trató de la primera ocasión en que se dibujaron los monumentos antiguos, como ya había ocurrido en otras naciones de la época. Las convulsiones políticas del reinado de Fernando VI conllevaron la suspensión del apoyo político y económico a Valdeflores, quien consiguió terminar el viaje a su costa. A pesar de la importancia que tenía el trabajo, la documentación quedó inédita en los archivos de la Real Academia de la Historia, donde se conserva en la actualidad.

Palabras claves: Viaje de España, Marqués de Valdeflores, Antigüedades, Monumentos, Catalogación, Patrimonio Arqueológico, Ilustración, Siglo XVIII.

El viaje de Luis José Velázquez de Velasco y Cruzado, Marqués de Valdeflores (Fig. 1), es el inicio de los denominados Viajes literarios, actividades que

\footnotetext{
* Doctor en Historia, especialidad Arqueología, por la Universidad de Sevilla. Miembro del Grupo de Investigación Historiografía y Patrimonio Andaluz (HUM 402), que bajo la dirección del Profesor Dr. D. José Beltrán Fortes, se encuentra adscrito al Departamento de Prehistoria y Arqueología de la Universidad de Sevilla. Es además miembro de la Sociedad Española de Historia de la Arqueología (SEHA) y de la Asociación Sevillana de Cronistas e Investigadores Locales (ASCIL). Email: jesussalasalvarez@gmail.com
}

Abstract: The Tour of Spain José Luis Velázquez de Velasco was the first attempt to catalog the antiquities of the nation, for later use in a new history of Spain. Powered by the Crown, which made available to the administrative apparatus, to use later obtained documentation on the issue of the Regional Board against the Papacy. It was the first time that ancient monuments were drawn, as had happened in other nations of the time. The political upheavals of the reign of Fernando VI involved the suspension of political and economic support to Valdeflores, who managed to finish the trip at his expense. Despite the significance that the work was unpublished documents originated in the archives of the Royal Academy of History, where it survives today.Despite the importance of the work was unpublished documents in the archives of the Royal Academy of History, where it survives today.

Key words: Spain Travel, Marqués de Valdeflores, Antiquities, Monuments, Cataloging Archeological Heritage, Illustration, Eightheenth century.

podríamos definir como aquellas expediciones realizadas por eruditos y anticuarios, con la finalidad de recopilar documentos originales de las historias eclesiástica y civil de la nación, que posteriormente serían utilizados por la política regalista borbónica para defender sus pretensiones frente a Roma.

Sobre estas empresas literarias, el propio Velázquez sostiene que "el reinado de Fernando VI forma en la Historia Literaria de la Nación Española una época muy notable. Por una precisa consecuencia de la paz, y de la abundancia de la Nación empezó a recobrar 


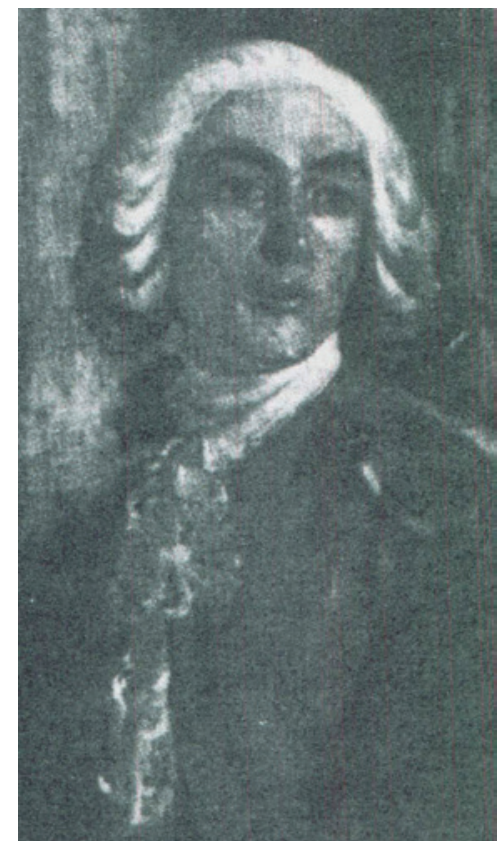

Figura 1. Retrato del Marqués de Valdeflores. Ayuntamiento de Málaga.

su antiguo vigor, reduciendo a su seno las Artes y las Ciencias tivas de este país, y propagando, y acreditando en él todos los ramos de los conocimientos humanos" (Velázquez 1765: 1-7).

Esta idea de los viajes no era una cuestión novedosa puesto que también durante el reinado de Fernando VI se creó el Patronato Regio, órgano al que se encargó de reconocer los archivos reales, catedralicios, eclesiásticos, locales y particulares, en busca de libros y documentos antiguos de primera mano, que justificaran y probaran las pretensiones de la Corona sobre su derecho a los beneficios eclesiásticos (Simón 1950; Béthencourt 1963: 76; Gómez 1985; Navarro 2004).

Igualmente, la Real Academia de la Historia comisionó en varias ocasiones a miembros de la institución para que fuesen a la Biblioteca del Monasterio de El Escorial, para consultar aquellos manuscritos y libros que eran necesarios para sus trabajos literarios (Huerta 1796: XXXVI).

Pero la Academia también había pensado en la posibilidad de conceder comisiones e instrucciones precisas a personas que residían en las provincias o que tenían que recorrerlas por razón de sus empleos y destinos, para que recogiesen, por cuenta de la institución, cuantas noticias de antigüedades y monumentos encontrase en archivos, bibliotecas, ruinas y obras públicas. Sin embargo, la falta de fondos económicos retrasó muchas veces a la institución de llevar a cabo su proyecto, contentándose únicamente con las noticias y descripciones que remitían los amantes de la anticuaria (Huerta 1796: XXXVII; cfr Almagro y Maier 2003: 5).

Pero dos hechos motivaron a la Real Academia de la Historia a solicitar del monarca la aprobación de una comisión, formada por un individuo de número de la institución, para recoger las antigüedades de todo el reino.

El primero de ellos fueron las noticias de las excavaciones realizadas en Cártama (Málaga), la antigua Cartima romana, en 1747 por el Teniente de Ingenieros Carlos Luján (Luxán 1876) y en 1751-1752 por Luis José Velázquez de Velasco (Rodríguez Oliva 1979; Salas Álvarez 2004: 582-586), en las que se hallaron los restos de un edificio de planta rectangular, con losas de mármol, en el que existían tres capillas o cellae ocupadas por diversas estatuas sedentes de deidades femeninas o de emperatrices divinizadas (Rodríguez Oliva 1980).

El segundo fue el pequeño opúsculo remitido por el galeno emeritense José Alsinet y Cortada a Agustín de Montiano y Luyando, en el que detallaba el estado de conservación de los monumentos emeritenses y transcribió las principales inscripciones romanas ${ }^{1}$ existentes (Hübner 1869: 55-72; Laurencín 1926: 80-87; Salas 2004: 95; Salas y León 2005: 88-89; Salas 2010: 36).

Asimismo solicitó del propio Montiano, como director de la Academia de la Historia, que trasladase esa carta al Monarca, "para que io tenga el consuelo quando pasen extranjeros de darle a conocer que también en España se aprecia la Historia de inscripciones $y$ monumentos antiguos". Montiano remitió esta petición al Marqués de la Ensenada, Secretario de Estado, al mismo tiempo que le solicitó la adopción de medidas concretas para "redimir de tan lastimoso abandono unas reliquias tan dignas de mejor suerte, a lo menos para asegurarlas en la memoria de los eruditos, que las supieran sacando algunas copias, y laminas en que acordasen nuestras sepultadas glorias"2.

Fernando VI aprobó esta idea y encargó al Marqués de la Ensenada que requiriese a la Academia de la Historia para que concretase la petición en un proyecto. Comunicada esta decisión a la Academia, Montiano requirió a Velázquez que presentase dicho proyecto, cosa que realizó el 16.07.1752 y el 04.08.1752 mediante dos Representaciones dirigidas a la Academia, en las que

1. Carta de 10.06.1752, remitida por José Alsinet a la Real Academia de la Historia. ARAH. CAG/9/7980/5(3). Las inscripciones remitidas por Alsinet fueron CIL II 464, 46, 468, 469, 472, 476, 478, $482,491,497,499,500,505,511,512,515,523,526,528,540,553$, $556,557,558,5559,563,564$, , 56, 571, 572, 576, 577, 579, 580, $581,583,585,586,587,591,593,597$ у 602.

2. Oficio de 16.06.1752 remitido por Agustín de Montiano y Luyando al Marqués de la Ensenada. ARAH. CAG/9/7980/5(5). 
incidió en la necesidad de completar el trabajo comenzado por el Patronato Regio, mediante la recopilación de los documentos históricos antiguos dispersos por toda España.

Agustín de Montiano y Luyando transmitió estas representaciones a Fernando VI a través del Marqués de la Ensenada ${ }^{3}$, proponiendo a Luis José Velázquez de Velasco y Cruzado para ejecutar el viaje.

La elección de Luis José Velázquez de Velasco vino motivada por varias cuestiones. En primer lugar, Velázquez había estudiado en el Colegio Imperial de San Miguel de Granada, donde conoció a Ildefonso Verdugo de Castilla, Conde de Torrepalma, con quien fundó la Academia del Trípode. Tras marchar a Madrid, Velázquez entró a formar parte en 1750 de la Academia del Buen Gusto, donde pudo departir con el propio Conde de Torrepalma, con Agustín de Montiano y Luyando, con el Marqués de la Ensenada, con Blas de Nasarre y con el Padre Rávago, los principales representantes de la erudición, de la política y del entramado administrativo del estado borbónico.

Además de estas relaciones político-culturales, Velázquez era Supernumerario de la Academia de la Historia, había practicado excavaciones en Cártama y acababa de publicar su ensayo sobre los alfabetos prerromanos (Álvarez 1996: 24-27; Maier 2002: 14; Almagro y Maier 2003: 6; Salas 2004: 97; Salas 2010: 37 , por lo que la Academia consideró que era la persona más idónea para materializar la empresa.

Aprobada la elección por el monarca, fue la propia Academia la encargada de redactar las reglas del proyecto, que recibieron la sanción regia mediante las Instrucciones que le dio en 2 de Noviembre de 1752 el Marqués de la Ensenada y que debía observar en el viaje que debía emprender para averiguar y reconocer las antigüedades de España (Canto 1994; Mora 1998: 44-45; Almagro 2002: 41-42; Maier 2002: 12-15; Almagro 2003: 37-38; Almagro y Maier 2003: 6-8; Salas 2004: 266-267; Salas y León 2005: 89-90; León Gómez 2006: 26, Manso 2010: 85: Salas 2010: 38), concediéndose a Velázquez para desarrollar su trabajo la protección real y una pensión de 36.000 reales $^{4}$ (Velázquez 1765: 6-7).

Pero este proyecto de catalogación de las antigüedades de la nación no era la primera vez que se

3. Oficio de 09.08.1752 remitido por Agustín de Montiano y Luyando al Marqués de la Ensenada. ARAH. CAG/9/7980/5(9) y CAG/9/7980/5(10).

4. ARAH. CAG/9/7980/5(16). En esa misma fecha, el Marqués de la Ensenada comunicó a Agustín de Montiano la Real Orden. ARAH. CAG/9/7980/5(17). planteaba. A comienzos del Siglo XVIII, Manuel Martí, Deán de Alicante, concibió un plan para "sacar a la luz y explicar las antigüedades de Hispania"5 (Mayans 1735: 287), si bien el proyecto no pasó de un mero intento fallido ante la falta de apoyo económico de la Corona, tal y como reconoció en propio Martí: "la deseada empresa no deja de ser costosa. ¿Con qué socorros pues recorreré la España? ¿visitaré las ruinas antiguas? ¿revolveré las cenizas abandonadas?. ¡Diréis que son las cosas del Soberano!. Ese solo recurso me queda, y quizás lo conseguiría de óptimo Príncipe" (León Gómez 2006: 56-58; Salas 2010: 36).

Pero ahora Velázquez tenía otras miras. Su objetivo era realizar una "colección general de todos los monumentos antiguos de España [que] no se podía hacer con solo el trabajo de entresacar las ya publicados de los libros impresos, por que ni se habian impreso todos aquellos monumentos de que habia noticia, ni habia noticia de otros monumentos que se hallaban esparcidos en diferentes pasajes y como sepultados entre las minas de los antiguos pueblos, en los gabinetes de los curiosos y en los archivos, bibliotecas antiguas, ni los pocos que se habían publicado estaban copiados con la mayor exactitud. Asi era preciso reconocer de nuevo los ya publicados, recoger los demás que no habían sido impresos y formar de todos ellos una amplia y exacta colección. Por otra parte, estos monumentos no podían ser entendidos sin un perfecto conocimiento de la Geografía del antiguo País, en que acontecieron los sucesos, a que ellos se refieren. La Geografía antigua de España era una cosa casi ignorada hasta entonces, y para formarla era necesario un gran número de observaciones que debían ejecutarse en los principales pueblos de todas sus Provincias" (Velázquez 1754: 139-143; Salas 2004: 255-256; León Gómez 2006: 2829; Salas 2010: 38).

Esta misma idea subyace en el texto de la Instrucción de 1752, donde se señalaba que el cometido a ejecutar era:

"5․- Registrará las ruinas de los famosos pueblos de la antigüedad y las reliquias de sus más suntuosos edificios como los teatros, anfiteatros, circos, naumaquias, acueductos, puentes, arcos de trofeo, templos, termas y sepulcros, los medirá, dibujará y explicará.

$6^{\circ}$.- Hará estas dimensiones por el pie de hierro que le habrá de entregar el Director de la Academia, en cuyo poder quedará otro igual al que llevare.

5. Carta de Martí a Montfaucon de fecha 08.03.1717. 
$7^{\circ}$.- Podrá hacer algunas ligeras excavaciones si fuere necesario para el desempeño de su Comisión, pero si estas debieren ser más largas, costosas o en perjuicio de alguno no las practicará sin representar antes a S.M. por medio del Director de la Academia para obtenerse su Real permiso.

$8^{\circ}$.- Copiará todas las inscripciones antiguas, asi de letras desconocidas como latinas, góticas, árabes $y$ hebreas y formará de todas ellas una colección.

$9^{\circ}$.- Recogerá las estatuas antiguas, basas, relieves, camafeos, piedras grabadas, medallas y demás reliquias comprobadas de la antigüedad, comprándolas de las personas que voluntariamente se determinen a venderlas, como su coste no sea excesivo, pues pasando de una cantidad moderada, esperará la Real aprobación antes de ejecutar la compra.

10'.- Cuidará de que todas estas alhajas se conduzcan a donde S.M. mandare y entretanto hará que las estatuas, bajorrelieves y demás monumentos cuya conducción no sea tan fácil se coloquen en parajes seguros y si puede ser en las casas de los Ayuntamientos de los Pueblos, encargando a los Justicias su conservación hasta que SM disponga de ellas.

$11^{\circ}$.- Llevará cuenta muy exacta y justificada de tolo lo que expendiere en estas excavaciones y compras y lo remitirá con cargo y data del dinero que se le fuere librando para estos gastos.

$12^{\circ}$.- Procurará ver los gabinetes de algunas personas particulares y observará en ellas cuanto pueda conducir a ilustrar y averiguar las antigüedades de España"6.

Varias cuestiones pueden analizarse del texto de la Instrucción. Por primera vez en nuestro país, se dispone, según se expresa en los apartados $5^{\circ}, 8^{\circ}$ y $9^{\circ}$ de la norma, una definición unitaria de lo que debían entenderse por monumento antiguo. Con esta consideración, Velázquez planteó la cuestión de que "no todos los monumentos antiguos son útiles" para la Historia, ya que existían "una infinidad de ellos, cuyo examen me deberá ser tan indiferente, como en las noticias que contienen lo son para la propia Historia".

Por ello, para realizar su trabajo se basó exclusivamente en los que él mismo denominó como "monumentos de pintura, escultura y arquitectura" (Velázquez 1754: 153-153v; Velázquez 1769: 19; Mora 1996: 904; Álvarez 1996: 75-102), tanto los vistos por el propio Velázquez como los existentes en otras publicaciones y manuscritos. Entre estos monumentos incluyó “1) templos; 2) fortalezas; 3) murallas; 4) puentes; 5) acueductos; 6) arcos; 7) sepulcros; 8) baños; 9) termas;

6. ASRAH 10.10.1752.
10) circos; 11) teatros; 11) anfiteatros; 12) naumaquias" (Velázquez 1754: 164v-167).

Posteriormente este apartado apareció denominado en la Noticia del Viage (1765) bajo el epígrafe de Monumentos de Pintura, Escultura y Arquitectura; instrumentos, muebles y utensilios de la vida civil, dividiendo el mismo en cuatro grandes grupos (Velázquez 1765: 117; Salas 2004: 264-265; Salas 2010: 40):

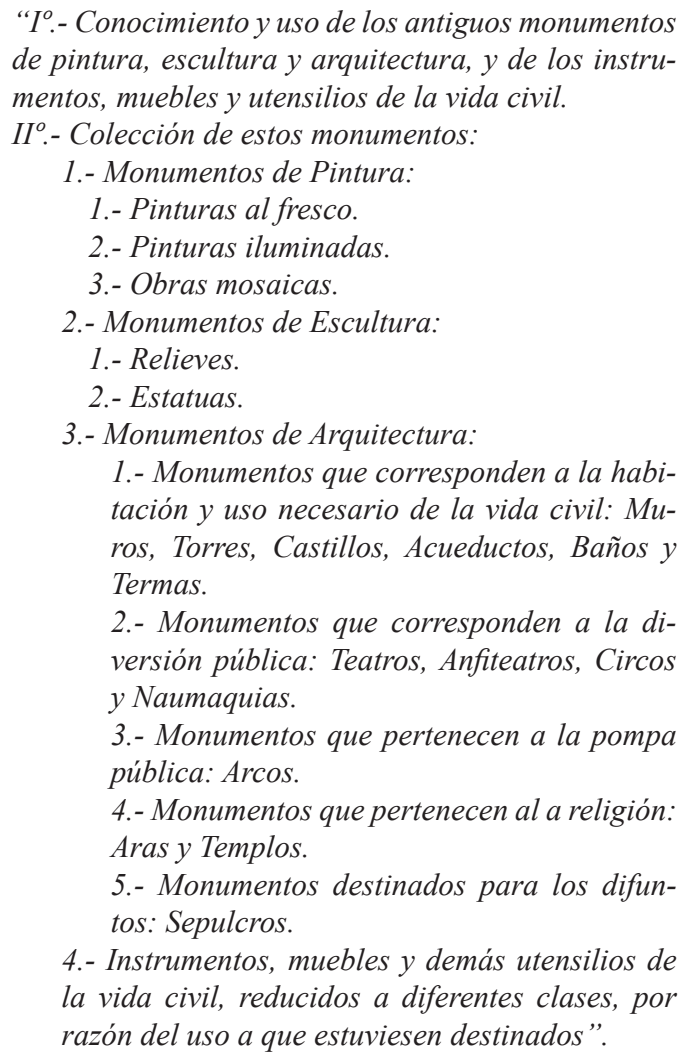

4.- Instrumentos, muebles y demás utensilios de la vida civil, reducidos a diferentes clases, por razón del uso a que estuviesen destinados".

Otra de las novedades fue que, por primera vez, se proyectó dibujar los monumentos con la mayor precisión y exactitud posibles, ya que el propio dibujo se concibió como un catálogo o inventario de los monumentos antiguos, en el que se recogía la representación visual de los sistemas constructivos y compositivos del monumento, es decir un álbum de anticuario, al que se acompañó una memoria explicativa de los mismos.

Este criterio de representación fue el adoptado para la conservación de las obra antiguas, sin que en ningún momento se pensase en la posibilidad de realizar obras de restauración. Es más, aunque se contemplaban la posibilidad de pequeñas excavaciones arqueológicas, estas nunca se pensaron como apoyo a una posible conservación, sino como un mero instrumento para obtener "piezas arqueológicas". 
Esta idea de representar los monumentos está influenciada por Bernard de Mountfaucon (1719-1724), erudito francés que consideraba como vestigio de antigüedad "únicamente [a] aquello que puede llegar a la vista y aquello que puede representarse mediante imágenes", de ahí que su obra se concibiera como un corpus de toda la antigüedad, donde se incluían conjuntamente la explicación y el diseño de los monumentos antiguos. Es decir, la imagen se convierte en un elemento fundamental y complementario para una descripción más pedagógica de las antigüedades.

Con la aprobación por parte de Fernando VI del proyecto de Velázquez de Velasco se disponía, por primera vez en nuestra Historia, que todo el aparato administrativo quedase al servicio de una persona concreta para realizar un proyecto que debía reportar numerosos beneficios a la nación.

Así, se dispuso que todos "los Capitanes y Comandantes Generales, a los Intendentes, Gobernadores, Corregidores, Justicias y demás personas a quienes toque, y se presentare este Despacho, faciliten al expresado Luis Velázquez todo el favor, auxilio y asistencia que pidiere y necesitare para el desempeño de su Comisión sin ponerle ni permitir se le ponga el menor impedimento ni dilación; y que le hagan franquear y poner de manifiesto los Archivos y Protocolos Públicos, que indicare, para sacar de ellos las noticias que le pareciere, y copias simples, o autorizadas de los Documentos, y demás Papeles que tuviesen conexión directa o indirecta con sus encargos, pues así conviene al Servicio de S.M." (Velázquez 1765: 8, nota 10; Álvarez 1996: 31).

En esta disposición administrativa también se indicó claramente el método de trabajo a seguir (Velázquez 1765: 8, nota 10; Canto 1994: 506; Álvarez 1996: 33). En primer lugar, debería dirigirse al Intendente, máxima autoridad administrativa provincial, quien debía informarle "de lo que haya digno de observación".

A este cargo, "después de presentarle el despacho supliqué me hiciese el favor de dirigir una Carta o Circular a todos los pueblos de su Intendencia, para que respondiesen al tenor de estas preguntas, que le entregué en una memoria: $1^{\circ}$.- Si el pueblo es ciudad, villa o aldea. $2^{\circ}$.- Si su situación es en alto o en llano. $3^{\circ}$.- Si junto a él pasa algún río o arroyo, hacia que parte del lugar, esto es, si por poniente, oriente, norte o mediodia. 4..- Con que otros lugares confina por poniente, oriente, mediodia y norte. $5^{\circ}$.- Cuales sean los últimos lugares de la Provinia por aquellas partes por donde esta confina. $6^{\circ}$.- Si en el pueblo o sus cercanías se encuentra alguna piedra con letras antiguas, estatuas, ruinas de algunos antiguos edificios, despoblados, medallas y otros vestigios de antigüedad.

Por medio de esta memoria quise recoger las noticias más importantes para las pesquisas de las antiguedades de los Pueblos"?.

Una vez "recogidas estas noticias, y las que en él pudiera adquirir del resto de la Provincia", realizaría, en segundo lugar, un itinerario de visita por todos "los demás lugares en que espere descubrir algo de importancia". A continuación, "en los pueblos grandes o en aquellos donde haya de practicar alguna diligencia concerniente a su comisión, se presentará antes a los Justicias con la orden que llevará de S.M., para que le auxilien y presten toda la asistencia que pidiere, franqueándole los Archivos y Registros Públicos para que saque de ellos las noticias que hubiere menester, certificadas y autorizadas en debida forma".

A pesar de lo dispuesto en la Real Orden, el sistema empleado por Velázquez para recopilar las antigüedades de un lugar fue otro distinto. En primer lugar, parte de la mención de la localidad en las fuentes grecorromanas, así por ejemplo de Sevilla dice que "es la antigua Hispal, como la nombra Mela y Silio Itálico, o Hispalis, según se escribe en Plinio y en Ausonio" (Velázquez s.a.-c: 23), para a continuación recoger todas las inscripciones existentes en obras anteriores, que siempre cotejó con su original, como realizó en el denominado Arco de los Gigantes de Antequera (Velázquez s.a-c: 27v-29v; Atencia 1981).

El fin perseguido era identificar las ciudades mencionadas en las fuentes grecorromanas con los restos que todavía eran visibles en el paisaje español. Así, por ejemplo situó Asta Regia en el "despoblado de la Mesa de Asta, entre Xerez y Trebujena, más cerca de Trebujena, donde se conservan algunas ruinas" (Velázquez s.a.-c: 27), a Siaro la situó a "2 y media leguas de Utrera hacia la parte de mediodía [sobre] un despoblado que llaman Sarracatin, y a sus inmediaciones Sarro, y es el sitio del Siarum que Plinio pone entre los pueblos del Convento de Hispalis", y a Nabrissa, la ubicó en la "villa de Lebrija, que todavía conserva algunos vestigios de antigüedad, principalmente en un arco romana, que se mantiene en la Plaza" (Velázquez s.a.-c: $30 \mathrm{v}-31$ ).

El Itinerario de Antonino y el Anónimo de Rávena también jugaron un papel importantísimo a la hora de realizar su trabajo, puesto que le sirvieron de guía para

7. Carta de 02.10.2753 remitida por Luis José Velázquez de Velasco a Agustín de Montiano y Luyando. ARAH. Mss. 9/6000, fols. $122-127 \mathrm{v}$ 
elaborar sus Observaciones del viaje a Extremadura y Andalucía y noticia de algunos pasajes de escritores antiguos $^{8}$, obra manuscrita que contiene el resultado de su viaje. En este trabajo se puede apreciar igualmente su profundo conocimiento de las obras del Obispo Jiménez de Rada, Ambrosio de Morales, Bernabé Moreno de Vargas, Antonio de Nebrija, Ginés de Sepúlveda y Pedro de Esquivel, a quienes denominó "Escritores históricos de las cosas de España", y de los que obtuvo numerosa información que posteriormente corroboró.

En cuanto a los epígrafes, Velázquez tenía la misión de "cotejar con sus originales estas copias defectuosas y copiarlos de nuevo", acabando así con la epigrafía de papel hasta entonces vigente (Canto 1994: 507; Maier 2002: 15), consistente en copiar sistemáticamente los epígrafes aparecidos en las distintas obras, sin corroborar su autenticidad o falsedad.

En su recorrido fue normal la compañía de algún "cicerone" local que le mostró las antigüedades o monumentos. Normalmente esta persona era un coleccionista o erudito local, miembro de las instituciones culturales borbónicas, como José Alsinet y Cortada, Livino Ignacio Leyrens y Pelleart, José Vázquez Venegas, Pedro Leonardo de Villacevallos, Fray Jerónimo de Estrada, Guillermo Tyrry, Fray Manuel Ruiz y Manuel Trabuco y Belluga.

Finalmente, la Instrucción disponía que la supervisión del proyecto recayese sobre la Real Academia de la Historia, a cuyo director Velázquez debía mantener informado del "curso de su viaje y lo que fuere practicando en él para que lo ponga en noticia de S.M. y si hubiere que prevenirle a donde se sepa se le han de dirigir las ordenes", lo que frecuentemente realizó Velázquez con Agustín de Montiano?.

Igualmente, la norma disponía que todos los monumentos deberían iban diseñados con la mayor exactitud posible, y representados "al vivo; y a sus diseños acompaña la descripción de cada uno en particular, con la noticia del lugar donde se encuentran. Se advierte si el autor los vio e hizo diseñar, o si recibió sus diseños de mano de otras personas que los vieron, y copiaron; con la noticia de los libros impresos o MSS de que se sacan los Monumentos de esta clase que no han podido cotejarse con sus originales" (Velázquez 1765: 124; Salamanques y Sánchez-Medina 2008; Salas 2010: 41).

8. RAH. Mss. 9/4118.

9. Velázquez de Velasco, Luis José, Epistolario de Velázquez con Montiano, BN. Mss. 17546. Sobre la figura de Velázquez de Velasco véase http://www2.uah.es/imagines cilii/Anticuarios/Textos/ velazquez.htm. Sobre los manuscritos de Velázquez en la Real Academia de la Historia, véase Abascal y Cebrián 2005: 465-490.
Para realizar estos dibujos se usó una "machina optica siempre que el terreno lo permitía" 10 , con la intención de conseguir una mejor calidad en sus obras. Desconocemos el tipo y las características de esta máquina, que seguramente estaba relacionada con los aparatos ópticos que empleaban los agrimensores e ingenieros militares, y que presentaba numerosas similitudes con la dioptra griega, que tiene un disco vertical que permite la representación de los alzados de los monumentos.

La obra de Velázquez incluyó inicialmente 49 monumentos de antigüedad de época romana, que se incrementó hasta 62 en la publicación de la Noticia del Viaje (Velázquez 1765: 125; Salamanques y Sánchez-Medina 2008) ${ }^{11}$. Algunos de los dibujos, como el del Arco de Caparra, se han perdido, mientras que otros fueron depositados en el Gabinete de Cartografía y Bellas Artes de la Real Academia de la Historia, y atribuidos inicialmente a José Córnide de Folgueira y Saavedra, si bien recientes trabajos de catalogación han corregido este error (Maier 2002: 134-135; Manso 2010).

Valdeflores tenía la obligación de llevar consigo un “diseñador" o dibujante ${ }^{12}$, siendo la persona elegida Esteban Rodríguez Tizón, profesor de la Academia de Bellas Artes y hermano del arquitecto Ventura Rodríguez. Según Juan Agustín Ceán Bermúdez, Esteban Rodríguez era "el mejor delineador que había entonces en la corte, educado en la escuela de su hermano" (Ceán Bermúdez 1832: 384; Salas y León 2005: 88; Manso 2010: 40-41; Salas 2010: 41). Esa escuela fue el ambiente familiar en el que Manuel Rodríguez, maestro de obras, debió inculcar a sus hijos Ventura y Esteban el interés y los rudimentos del dibujo ${ }^{13}$.

Esta importancia dada al dibujo se plasmó en una representación y descripción de las antigüedades novedosa en su época, al adoptarse por primera vez un lenguaje y unos criterios representativos mucho más arquitectónicos y no tan pintorescos como se venían realizando hasta ese momento.

10. Oficio de fecha 02.10.1753 remitido por Luis José Velázquez de Velasco a Agustín de Montiano. ARAH. CAG/9/7980/5(42).

11. En el Mss. $9 / 4118(9)$ y 9/4118(10) de la RAH, se conserva la lista de los monumentos del tomo $1^{\circ}$ de su obra.

12. RAH. Mss. 9/4160 y 11/8055/32.

13. Ventura Rodríguez continuó posteriormente su aprendizaje de los rudimentos del dibujo con los arquitectos E. Marchand, encargado de las obras del Palacio de Aranjuez, y Filippo Juvara, encargado de las obras del nuevo Palacio Real. Sobre la formación posterior de Esteban Rodríguez y el devenir de sus dibujos en la Academia de la Historia, véase el trabajo de Carmen Manso Porto (Manso 2010), quien incluye el listado de los dibujos conservados en el Gabinete Cartográfico y Artes Gráficas de la Real Academia de la Historia. 
Con la elección "intencionada” de Esteban Rodríguez Tizón, Velázquez de Velasco buscaba el favor del arquitecto Ventura Rodríguez, importante personaje de la corte. Esta decisión le hizo posicionar a favor de las teorías del arquitecto, que en el mismo año de 1752 logró el cargo de director de Arquitectura de la Real Academia de Bellas Artes de San Fernando, que defendía un método de aprendizaje de la Arquitectura basado en las estampas y dibujos de Vignola y en el Barroco italiano de Maderno, Bernini, Borromini y Fontana.

Esteban Rodríguez no participó en la parte correspondiente a Andalucía, pues a finales de 1753 volvió a Madrid, donde fallecería en 1754. Esta ausencia del dibujante se notó especialmente en el trabajo sobre Andalucía, pues no conocemos al encargado de realizar los dibujos, en los que se observa una ausencia de rigor científico, pues los diseños de los monumentos se reducen a simples bocetos de alzados y plantas, en los que en ningún momento existen ni medidas ni proporciones exactas.

Esta posición difiere por la mantenida por otros autores (Maier 2010: 142, 7; Manso 2010) que defienden la presencia de Esteban Rodríguez en Andalucía, donde dibujaría algunos monumentos, en especial el Teatro de Acinipo (Ronda la Vieja, Málaga) (Maier 2001: 212, ficha 17), pero en realidad se trata del Teatro de Mérida (Manso 2010: 56-58, fig. 14), como se aprecia en las claras diferencias existentes entre ambos dibujos. Lo cierto es que Velázquez conocía el yacimiento de Acinipo por una visita anterior en 1750, y cuando visitó por segunda vez el lugar, llevaba la descripción anterior y el dibujo del Teatro de Mérida para realizar comparaciones entre ambos edificios. La confusión posterior vendría al ser entregadas a la Academia de la Historia todos los papeles de Velázquez por sus herederos.

La realización física y material del viaje estuvo marcada con los sucesos políticos acaecidos tras la destitución política del Marqués de la Ensenada (Álvarez 1996: 32), que era el principal valedor político del proyecto de Valdeflores. A partir de este suceso, podemos distinguirse tres etapas o períodos en la realización del programa:

\section{PRIMERA ETAPA (1 DE DICIEMBRE DE 1752 A 9 DE NOVIEMBRE DE 1753)}

Velázquez de Velasco y Esteban Rodríguez parten de Madrid en dirección a Extremadura (Velázquez 1765: 16-18), para realizar su trabajo. La opción del lugar por el que comenzar las labores no fue una cuestión casual, ya que la elección de Mérida como primera etapa se debió, según J. Maier (2002: 15) a "que era alli donde mayor número de monumentos visibles se conservaban, tantos, según Alsinet, como en la propia Roma".

Sin embargo, la causa de la elección bien pudo ser otra distinta. Antes las noticias remitidas por José Alsinet $^{14}$, la Academia consideró que dada la "certidumbre de que aun hay más vestigios de Templos, Amphitheatro, Naumachia, Arco, Puente, y sobre todo un Circo Máximo, monumento que tal vez no tendrá segundo en la Europa fuera de Italia15" (Salas y León 2005: 89), debía ser Mérida el lugar de comienzo del viaje para así poder conocer de primera mano aquellas antigüedades que tanto llamaban la atención a los extranjeros que pasaban por la ciudad en su camino desde Lisboa a Madrid, y adoptar las medidas necesarias que asegurasen su conservación.

La decisión de Velázquez de realizar una serie de estudios acerca de la validez del denominado "pie español", hace que podamos distinguir tres fases sucesivas en su estancia extremeña:

\section{Primera fase: el estudio de los monumentos de Emérita Augusta.}

Velázquez llegó a Mérida el 18 de Diciembre de 1752, y desde ese mismo momento comenzó "à examinar el gran numero de monumentos antiguos, $q$ [ue] se hallan en Mérida: dos puentes, dos aqueductos, un Alcazar ó fortaleza Romana, un Circo, una Naumachia, un theatro, un tropheo, un templo, estatuas, baxos relieves, inscripciones, $y$ otras diferentes antiguedades que se midieron, $y$ diseñaron al vivo" 16 , realizando un total de 20 dibujos de los principales monumentos emeritenses.

Velázquez realizó una serie de excavaciones en el graderío del teatro de Mérida, para documentar las estructuras del edificio que permanecían cubiertas de escombros y tierra (León Gómez 2006: 136-137; Salas y León 2005: 90; Salamaques y Sánchez-Medina 2008), y que le permitieron realizar una importante y novedosa descripción del edificio (Velázquez s.a.-c: 25-26v).

14. Carta de fecha 10.06.1752, remitida por José Alsinet a la Real Academia de la Historia. ARAH. CAG/9/7980/5(3).

15. Oficio de 16.06.1752, remitido por Agustín de Montiano y Luyando al Marqués de la Ensenada. ARAH. CAG/9/7980/5(5).

16. Oficio de fecha 02.10 .1753 remitido por Luis José Velázquez de Velasco a Agustín de Montiano. ARAH. CAG/9/7980/5(42). 


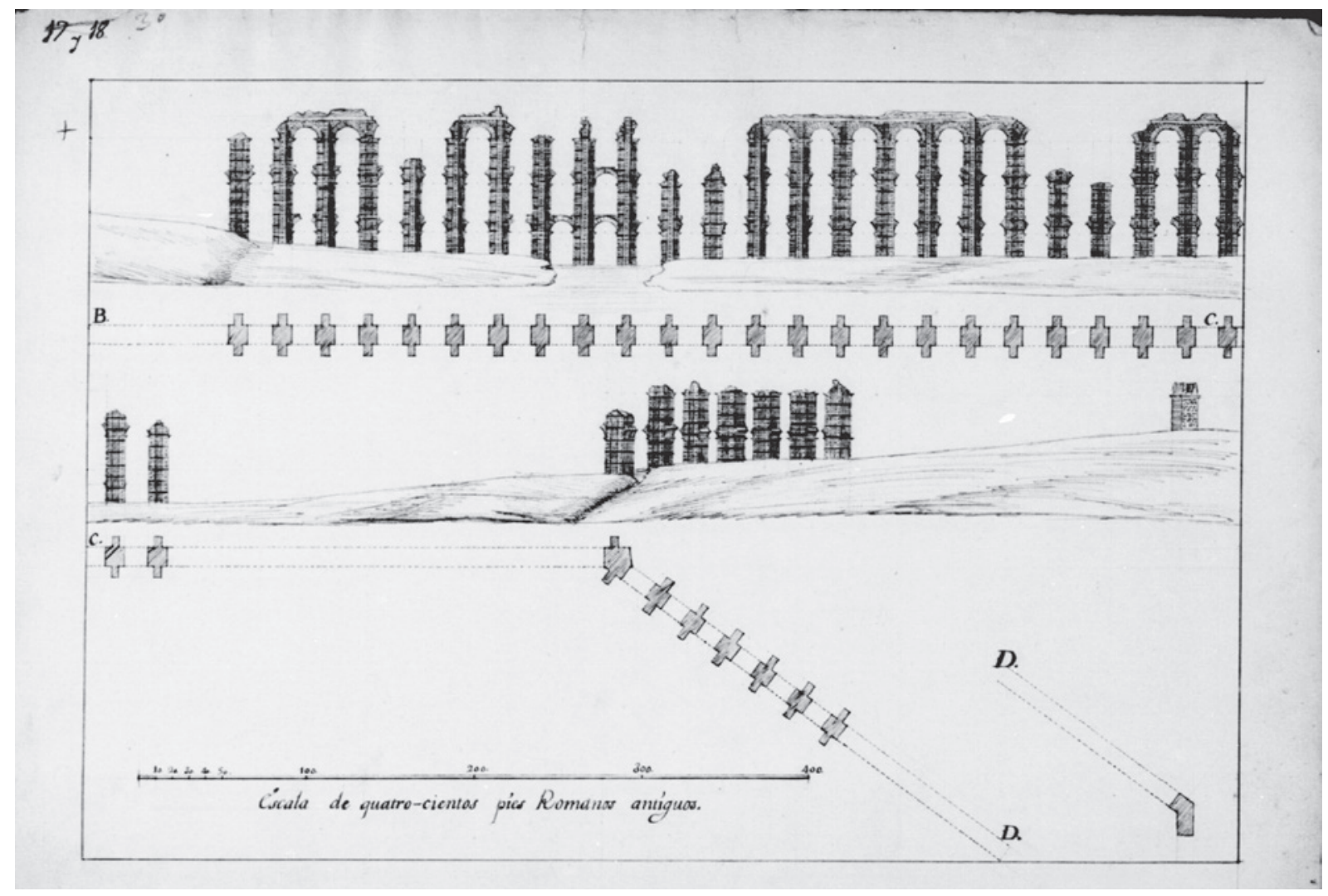

Figura 2. Acueducto de Los Milagros. Dibujo de Esteban Rodríguez. Gabinete Cartográfico de la Real Academia de la Historia. Sign. BA-VI e 87.

Tras estudiar el Puente sobre el río Albarregas (Velázquez s.a-c: 23v), centró su atención sobre los Acueductos de San Lázaro y de los Milagros, que abastecían de agua a la colonia romana. Sobre el segundo (Fig. 2), dice que "entra por el Oriente, y biene de mui lexos por la parte del Norte caminando con varias bueltas hasta la ciudad. Su canal es de 2 pies de ancho, y 4 de alto, con 4 pies y diez dedos de gruezo. Luego que daba vista a la ciudad, se empezaba a elevar sobre grandes arcos, que suplian la desigualdad del terreno" (Velázquez s.a.-c: $23 \mathrm{v}-24)$.

Cerca del Acueducto se encontraban los restos del Circo Romano (Fig. 3), que era uno de los monumentos que más interesaba a la Real Academia de la Historia. Según Velázquez, el edificio medía "de largo 1356 pies, de ancho 3334, y el gruezo de los muros, que le rodean, es de 31 pies y 11 dedos". Respecto al estado de conservación manifiesta Velázquez que "aunque la maior parte de estos muros esta arruinada, no dexan de distinguirse bien por algunos lados los podios, subselios, y caveas, y las dos únicas entradas que parece tenía este Circo por la parte del Septentrion. La spina del estadio se conoce mui bien; tiene de ancho 29 pies y 3 dedos, de alto 4 pies, y de las dos mitades, en que esta dividido, la entera tiene 344 pies de largo" (Velázquez s.a.-c: $24 \mathrm{v}-25$ ).

El Anfiteatro (Fig. 4), o Naumachia, tenía "por la parte exterior de un lado a otro, tenia de largo 381 pies, $y$ de ancho 327". Dado que en su mayor parte se encontraba cubierta de tierras, Velázquez no pudo calcular la altura existente "desde el plan interior hasta las primeras gradas, [ya] que en este intervalo havia un muro con la altura correspondiente para contener dentro de sí todo el agua necesaria para las naves" (Velázquez s.a.-c: 26v-28).

Otro edificio que merece la pena destacar de la descripción de Velázquez es el denominado Templo de Diana, ubicado en la llamada Casa de los Milagros, al que define como un "templo antiguo de orden compuesto, y de los que Vitrubio llama peripteros, por tener seis columnas en la frente, otras tantas en la espalda, y once en cada lado. Las columnas son striadas, y constan de varios trozos de piedras: su altura con la baza, $y$ capitel es de 37 pies, $y 8$ dedos (Fig. 5); el diámetro 


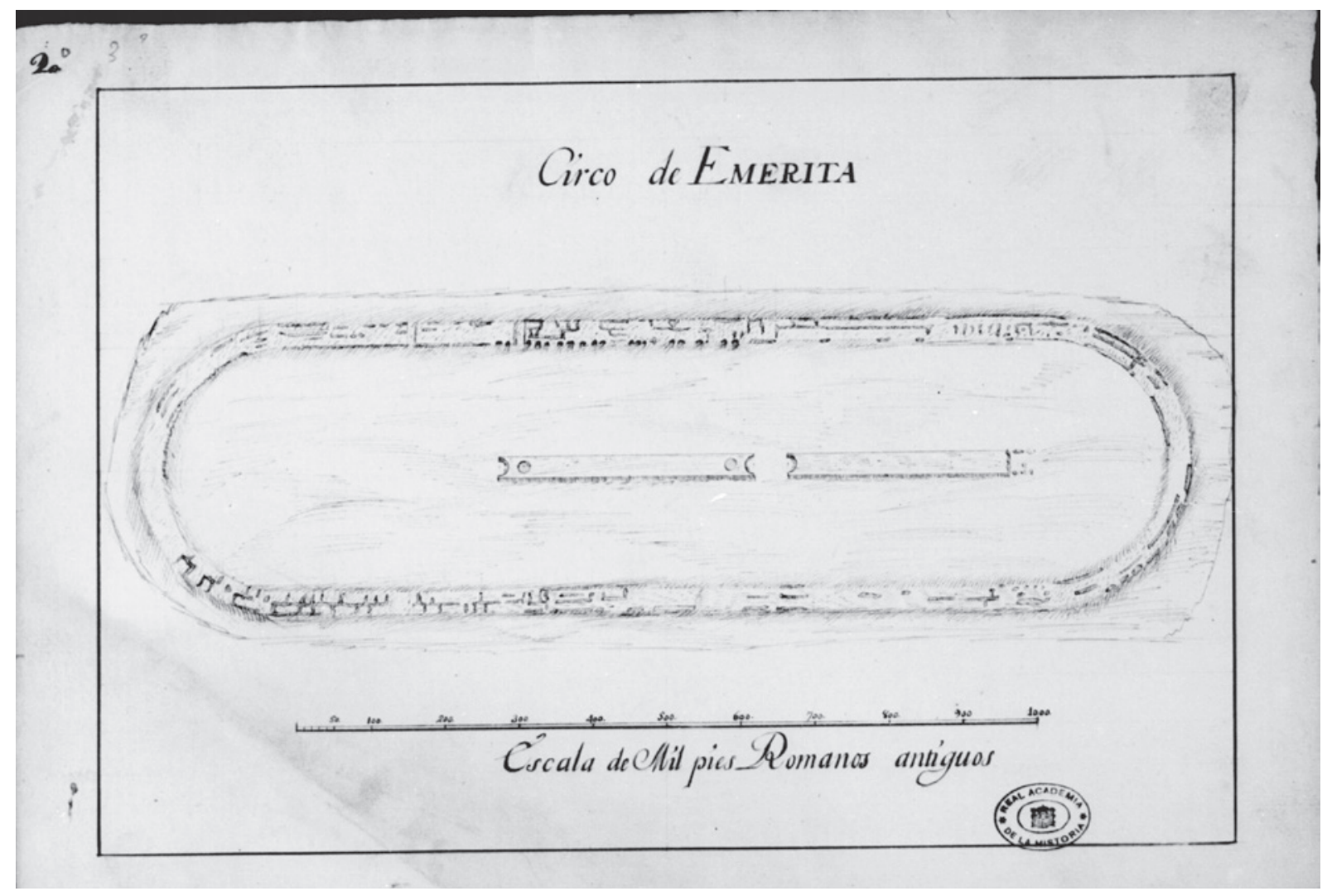

Figura 3. Planta del Circo de Mérida. Dibujo de Esteban Rodríguez. Gabinete Cartográfico de la Real Academia de la Historia. Sign. BA-VI e 92.

inferior de la columna de 4 pies y el superior de 3. Las bazas tienen de alto 3 pies; los capiteles 3 pies y 8 dedos de alto: y la diagonal de su ábaco 7 pies, y 8 dedos de largo: los architrabes 2 pies de alto; los intercolumnios 6 pies y 8 dedos de ancho; y el intercolumnio que forma la puerta del templo, tiene de ancho 13 pies. Supliendo en uno y otro lado las columnas, que faltan hasta once, parece que tendría de largo 96 pies, y de ancho por la fachada 63. En las dos columnas, que están a los dos lados de la entrada hai una hendidura larga, que las corta hasta la baza, y serían de algunas rejas de hierro, que servirían de puertas al templo por aquella parte. No se ha podido descubrir monumento alguno, por donde pueda rastrearse el nombre de la Deidad a que este templo fue consagrado" (Velázquez s.a.-c: 28v-29; Álvarez Martínez 1976; Álvarez Martínez 1991; Nogales y Álvarez Martínez 2003: 40-41; Salamanques y Sánchez-Medina 2008).

Otro edificio destacado por Velázquez fue el Templo de Marte (Fig. 6), situado "en la plaza de Santiago, donde se descubrieron los mármoles que oi estan en la Capilla que dicen Horno de Santa Eulalia extramuros de la Ciudad. Estos componían parte del antiguo portico del templo, según se comprende por su misma labor. Los fragmentos, que oi restan, son quatro trozos enteros () de Architrave, friso y cornisa; los pedazos ( ) de otros dos; y otras tantas columnas con sus Capiteles de orden Corintio. El primer mármol tiene sobre el friso esta inscripción:

\section{MARTI.SACRUM \\ VETTILLA. PACULI}

Y por ella se sabe, que Vettila muger de Paculo, fue quien erigió á Marte este templo. Las Letras de la primera linea tienen 7 dedos de alto; y las de la segunda 6, y assi unas como otras $1 / 2$ dedo de profundidad. Dentro de las mismas letras se ven otras cavidades más hondas de 1/2 dedo de profundidad; y servían para introducir en ellas las grapas que sugetaban el metal de que las letras estaban embutidas. Parece que no solo las letras, sino también todo el espacio que ocupa la inscripción, estaba cubierto con otra plancha de metal; por que la superficie del cuadrilongo en que las letras 


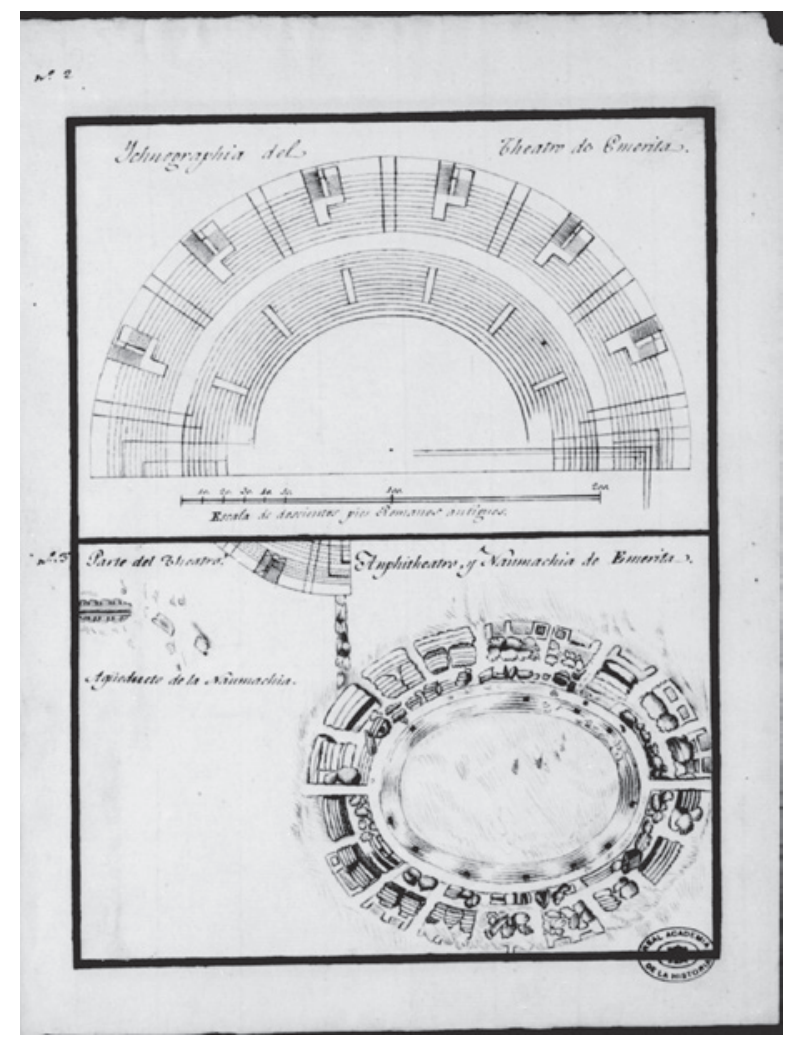

Figura 4. Planta del Teatro y Anfiteatro de Mérida. Dibujo de Esteban Rodríguez. Gabinete Cartográfico de la Real Academia de la Historia. Sign. BA-VI e 91.

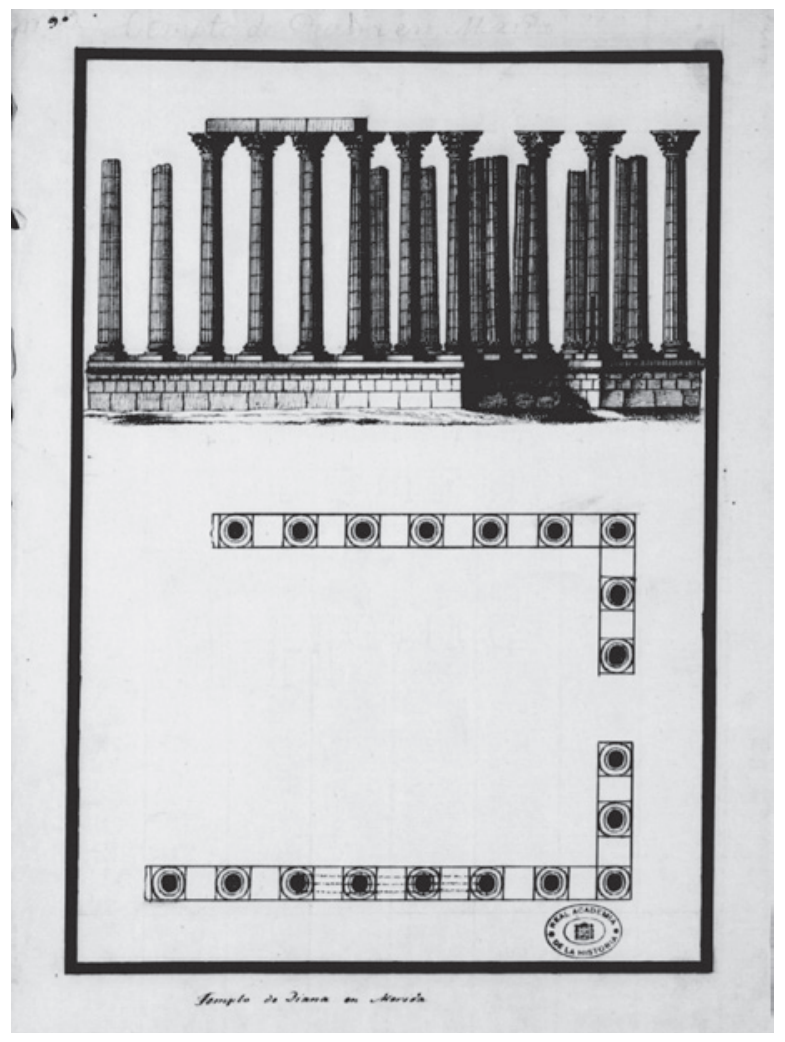

Figura 5. Alzado y Planta del Templo de Diana de Mérida, elaborado por José Córnide a partir de los datos de Velázquez de Velasco y Esteban Rodríguez. Gabinete Cartográfico de la Real Academia de la Historia. Sign. BA-VI e 83.

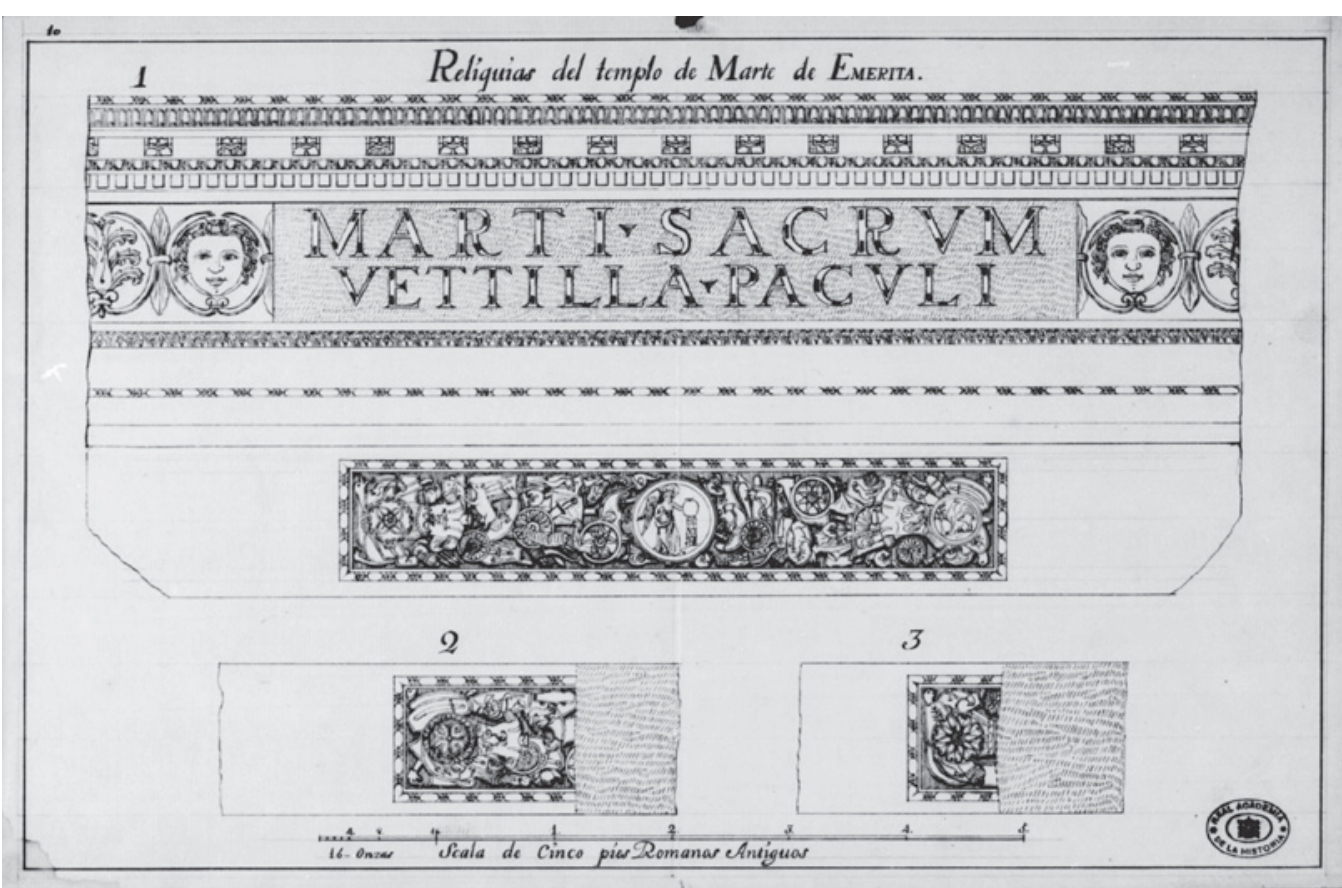

Figura 6.

Arquitrabe del Templo de Marte de Mérida. Dibujo de Esteban Rodríguez. Gabinete Cartográfico de la Real Academia de la Historia. Sign. BA-VI e 79-82. 


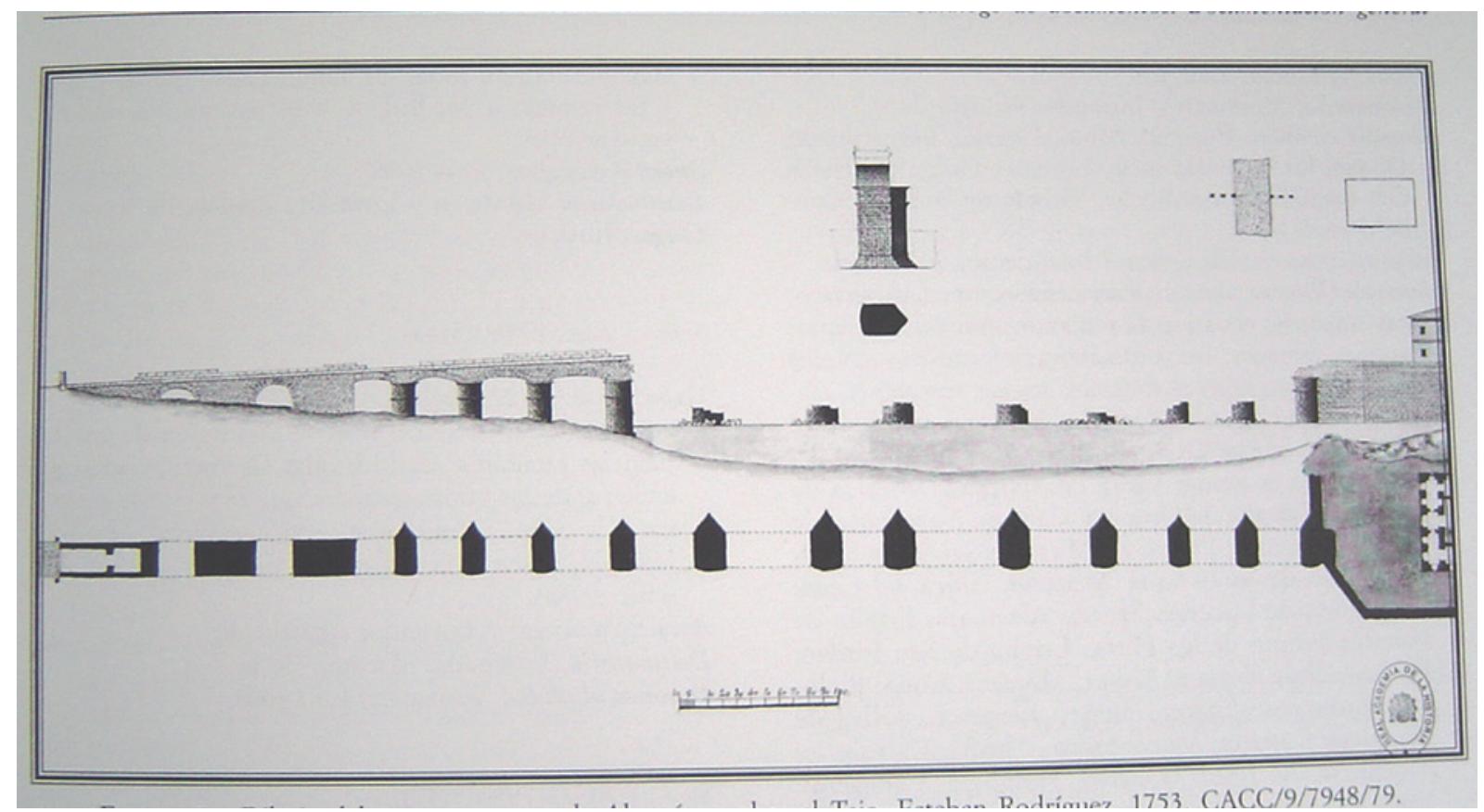

Figura 7. Alzado del Puente Romano de Alconétar sobre el Tajo, realizado por Esteban Rodríguez. Dibujo de Esteban Rodríguez. Gabinete Cartográfico de la Real Academia de la Historia. Sign. BA-VI e 93bis.

se extienden, no está lisa, y bruñida como lo restante del friso, sino escabrosa, y sin pulir; de que se infiere, $q$ podría estar cubierta con alguna la mina de metal, en que sobresaliesen las letras de la inscripción. Esta manifiesta desde luego, que el friso en que está esculpida era el principal de la fachada del Portico del Templo. Los adornos del friso son ciertas flores interpoladas con una cabezas, al parecer de muger, colocadas de frente, con el pelo tendido, y en lo alto dos alas, de que se puede comprehender, que representen la victoria.

En el Paflon de este marmol se ven grabados de relieve diferentes trofeos de guerra. En el medio hai un gran medallon, $y$ en él una victoria en pie, buelta acia la izquierda, teniendo en la mano derecha el instrumento de que usaban los antiguos para escribir en lugar de pluma, y con la siniestra sostiene un escudo colocado sobre el tronco de una palma" (Velázquez s.a.-c: $29-32 \mathrm{v}$ ).

\section{Segunda Fase: la Vía de la Plata y sus investigaciones sobre el pie romano.}

En la descripción y diseño de los monumentos emeritense Velázquez utilizó el pie romano antiguo, a pesar de que en la Instrucción de 1752 le obligaba expresamente a utilizar el pie castellano.
Ello fue debido a que algunas de las medidas dadas por el Maestro Pedro Esquivel, el erudito que estableció las dimensiones del pie castellano, no podían ser corroboradas por encontrarse transformados los monumentos en los que se basó, de manera que era imposible localizar los puntos de referencias utilizados por éste. Esta circunstancia hizo dudar a Velázquez de la teoría de Esquivel, por lo que se decantó por usar el pie romano antiguo.

No contento con ello, planteó a la Academia de la Historia la posibilidad de cotejar ambas unidades mé$\operatorname{tricas}^{17}$. Para poder llevar a cabo esta comprobación, solicitó y obtuvo del monarca el permiso para recorrer la antigua Vía de la Plata hasta Salamanca ${ }^{18}$, donde aun se conservaban en su sitio "muchas de las piedras antiguas, que señalaban las millas [y] que se pusieron al tiempo que [se] hizieron la Calzada" (Velázquez s.a.-c.: 3), y que fueron la base de los estudios del Maestro Pedro Esquivel (Manso 2010: 48 y 50).

Velázquez aprovechó este pequeño viaje para estudiar los monumentos que encontró a su paso por

17. Oficio de fecha 17.03.1753 remitido por Luis José Velázquez de Velasco a Agustín de Montiano. ARAH. CAG/9/7980/5(30).

18. Oficio de fecha 20.04.1753 remitido por Agustín de Montiano y Luyando a Luis José Velázquez de Velasco. ARAH. CAG/9/7980/5(35) 


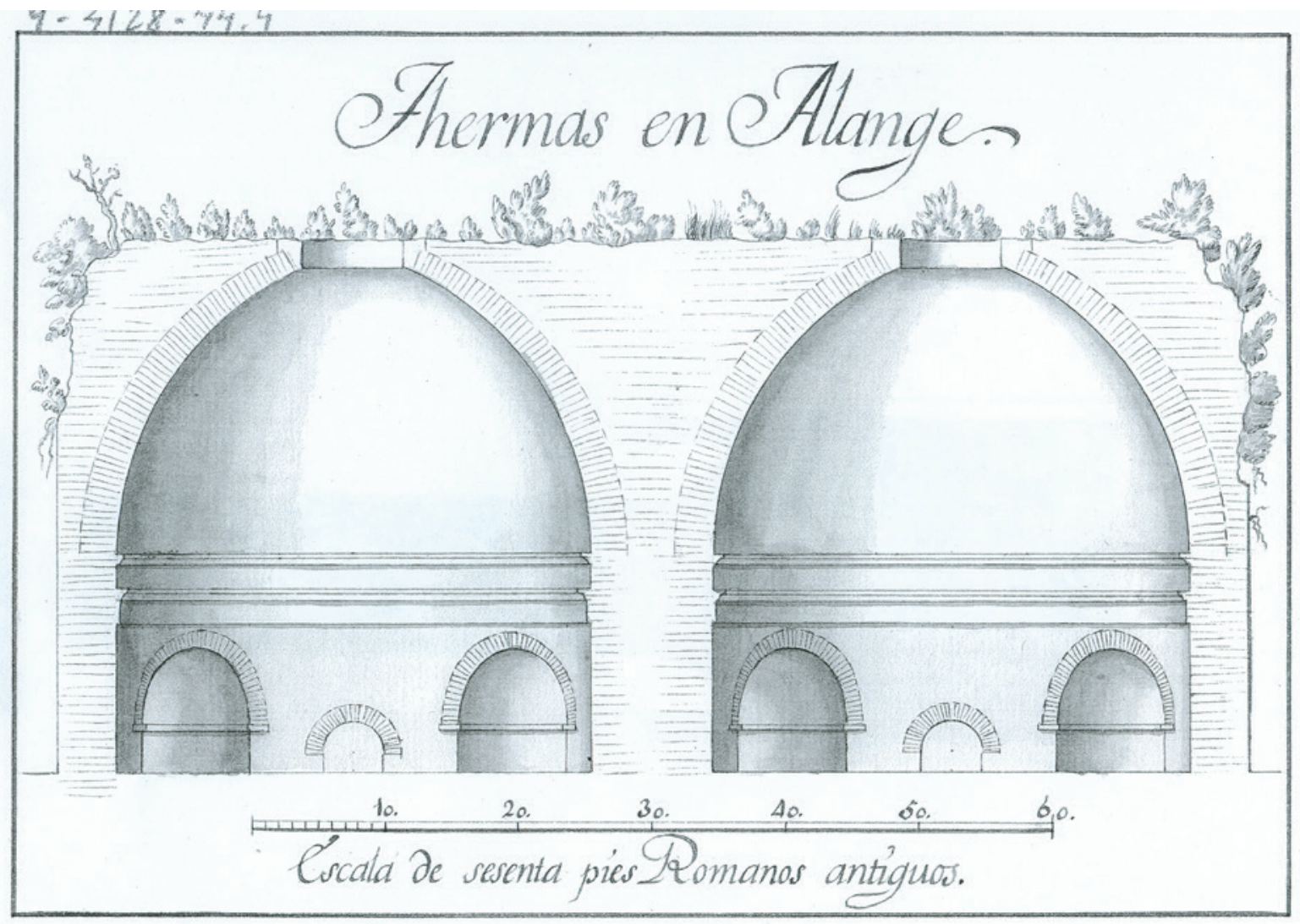

Figura 8. Alzado de las Termas de Alange. Dibujo de Esteban Rodríguez. Archivo de la Real Academia de la Historia. Mss. 9-4128-44.4.

la provincia de Cáceres, como es el caso (Fig. 7) del Puente Romano de Alconétar o Mantible (Velázquez s.a.-c.: 5v; Maier 2002: 129, 5) sobre el río Tajo.

A continuación se dirigió hacia las ruinas de Caparra (Oliva de Plasencia), donde describió el tetrapylon o arco cuadrifonte de época flavia ${ }^{19}$, al que Velázquez definió como un "arco de orden compuesto cuias ruinas permanecen sobre la calzada antigua que va a $\mathrm{Sa}$ lamanca, y pasa por debajo de él. Lo que oi ha quedado, es una boveda sostenida de quatro arcos abieros por todos quatro frentes. Por la parte interior de la bovedad, y por algunas de los quatro frentes se ven entre las uniones de las piedras muchos agujeros, en que estubieron encajados los garfios de hierro que se ponian en semejantes edificios, como se ve todavia en el arco de Merida, pues en semejantes edificios servian para colgar y sostener los despojos y tropheos militares. Delante de

19. Por la documentación de Velázquez, sabemos que Esteban Rodríguez realizó un dibujo de esta construcción, imagen que hoy en día ha desaparecido. La lista completa de los dibujos de Esteban Rodríguez la encontramos en el trabajo de C. Manso (Manso 2010: 60-72). los pilastrones de la frente hai otras dos pilastras pequeñas, sobre las quales hubo sin duda algunas estatuas. Una y otra pilastra tubieron sus inscripciones, que el tiempo ya ha destruido" (Velázquez s.a.-c.: 7).

\section{Tercera Fase: los monumentos existentes en el Camino a Andalucía}

Tras regresar a Mérida, Velázquez continuó su viaje hacia Andalucía, recogiendo cuantos monumentos e inscripciones encontró en su recorrido, muchos de los cuales tenía conocimiento previo gracias a las informaciones que le proporcionó José Alsinet.

En Alange (Badajoz) situó el Castrum Colubri de las fuentes clásicas por la abundancia de restos arqueológicos, entre los que sobresalían los restos de unas termas, a las que Ambrosio de Morales había considerado como "templo antiguo de tiempo de los Romanos, redondo como el Pantheon de Roma" (Morales 1575: 97).

Sin embargo, Velázquez describió este edificio romano (Fig. 8) como "hecho todo de argamaza, pizarras 
y piedras ordinarias. Su es quadrada oblonga ... [que se divide] en dos aposentos redondos [dentro de los que] se descubren quatro bovedas, o nichos semicirculares [que] no tenían más luz que la que entra en cada uno de ellos por una claraboya ...colocada en lo alto de la boveda" (Velázquez s.a.-c.: 39-40; cfr. Álvarez Martínez 1972; Álvarez Martínez 1973: 447-449; Carmona 1999).

El otro monumento al que prestó atención fue un trofeo erigido a Trajano (Fig. 9) que servía de campanario a la Iglesia Prioral de Zalamea de la Serena (Badajoz).

Según Velázquez "se trata de un cuerpo quadrado, de piedra, y mazizo" sobre el que se elevaban "dos columnas striadas, compuestas de diferentes piedras" (Velázquez s.a.-c: 41), que fue levantado en el cuarto año del reinado de Trajano para conmemorar sus victorias sobre los Dacios.

Sin embargo, los estudios de A. García y Bellido consideran al monumento como un Dístylo Sepucral de época flavia, con numerosos paralelos en Siria, y perteneciente a la necrópolis de la antigua Iulipa (García y Menéndez 1963; García Bellido 1979: 311-312, 512).

\section{SEGUNDA ETAPA: 10 DE NOVIEMBRE DE 1753 A 31 DE DICIEMBRE DE 1754}

Velázquez de Velasco entró en Andalucía ${ }^{20}$ sin dibujante alguno, puesto que Esteban Rodríguez debió volver a Madrid, donde falleció en 1754. Esta ausencia se notó en el trabajo, pues los monumentos y antigüedades que recoge en su trabajo van acompañados de meros apuntes o bocetos, sin escala o referencia alguna.

Durante este período (Velázquez 1765: 16-18) recorrió las distintas provincias andaluzas, visitando yacimientos, anotando y dibujando monumentos y piezas componentes de las colecciones particulares, y remitiendo numerosas monedas, dibujos, inscripciones y piezas arqueológicas a la Academia de la Historia.

En Singilia Barba (Despoblado de El Castillón, Antequera, Málaga) visitó las ruinas de la antigua ciudad romana, entre las que sobresalían "los restos de un theatro casi del todo destruido, y solo han quedado los vestigios del semicírculo de las gradas hasta los extremos por donde se unían con la scena. El diámetro de este semicírculo por dos extremidades es de 407 pies españoles antiguos de a tercia de vara castellana", realizando

20. Oficio de fecha 10.11.1753 remitido por Luis José Velázquez de Velasco a Agustín de Montiano. ARAH. CAG/9/7980/5(5).

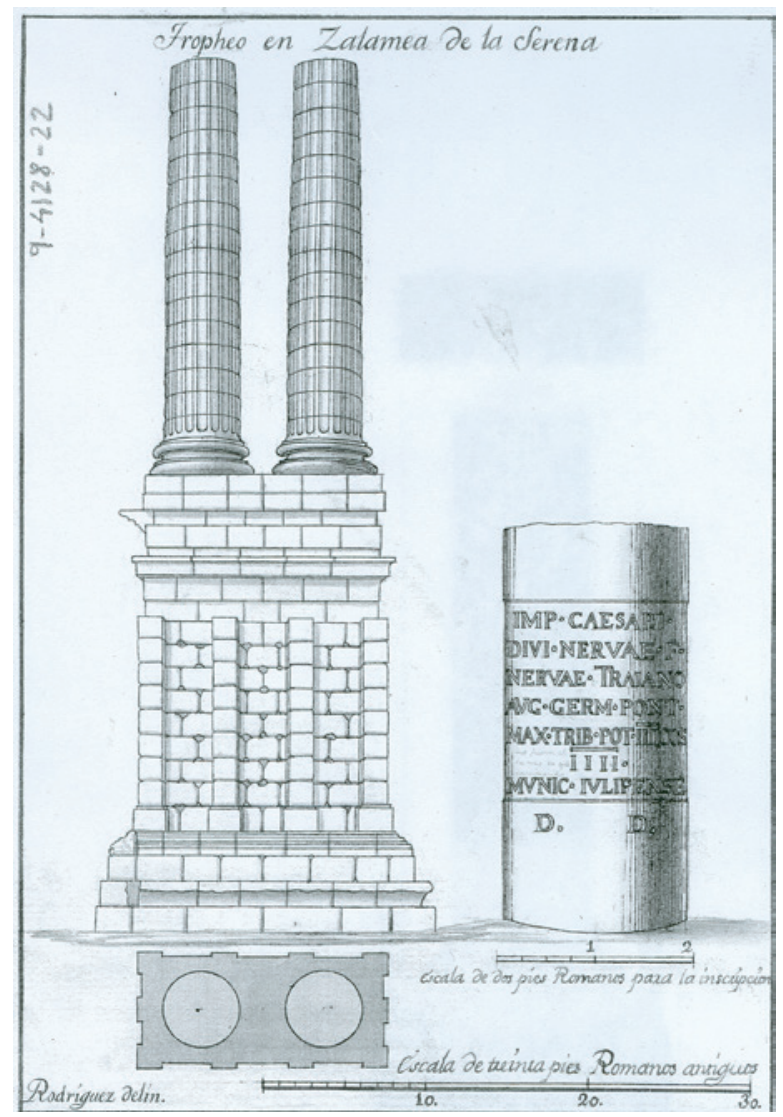

Figura 9. Tropheo de Zalamea de la Serena (Badajoz), dibujo de Esteban Rodríguez. Archivo de la Real Academia de la Historia. Mss. 9-4128-22.

un croquis (Fig. 10) de la planta del edificio ${ }^{21}$. Velázquez sostuvo que el estado de destrucción del edificio era debido a su utilización como cantera para la " $f a ́$ brica del Convento de San Juan de Antequera" (Velázquez s.a.-c: 29v-30; Thouvenot 1940: 438; Atencia 1998: 55 y 58, 6; Salas 2010: 44 y 182-183).

Otro edificio que visitó fue la llamada Torre de las Bóvedas (San Pedro de Alcántara, Málaga), que ya conocía gracias a la obra de Macario Fariñas del Corral. Allí dibujó un edificio (Fig. 11) construido en "argamasa tan desecho, que apenas se ha podido ajustar sus partes a las debidas dimensiones", que Velázquez atribuyó erróneamente, al compararlo con otras edificaciones abovedadas, a una "antigua almadraba o pesquería" (Salas 2010: 44 y 181-182), cuando en realidad se trata de los restos de un edificio termal de época antoniniana de la ciudad romana de Salduba (Beltrán Fortes 2008b:203)

21. El dibujo del teatro se encuentra en el Mss. 9/4128 y fue publicado por R. Thouvenot. 


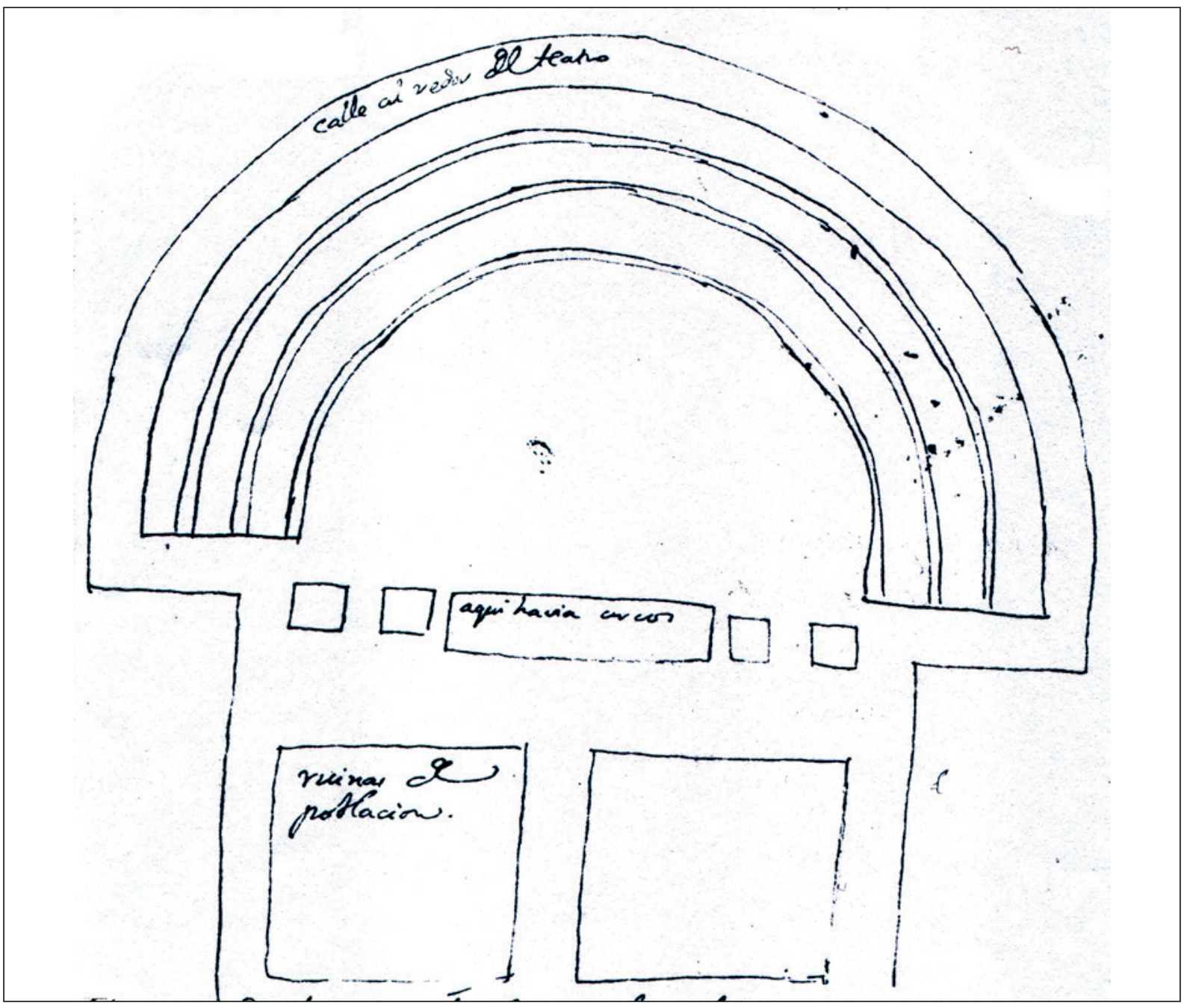

Figura 10. Planta del Teatro de Singilia Barba, según L.J. Velázquez. Archivo de la Real Academia de la Historia. Mss. 9-4128.

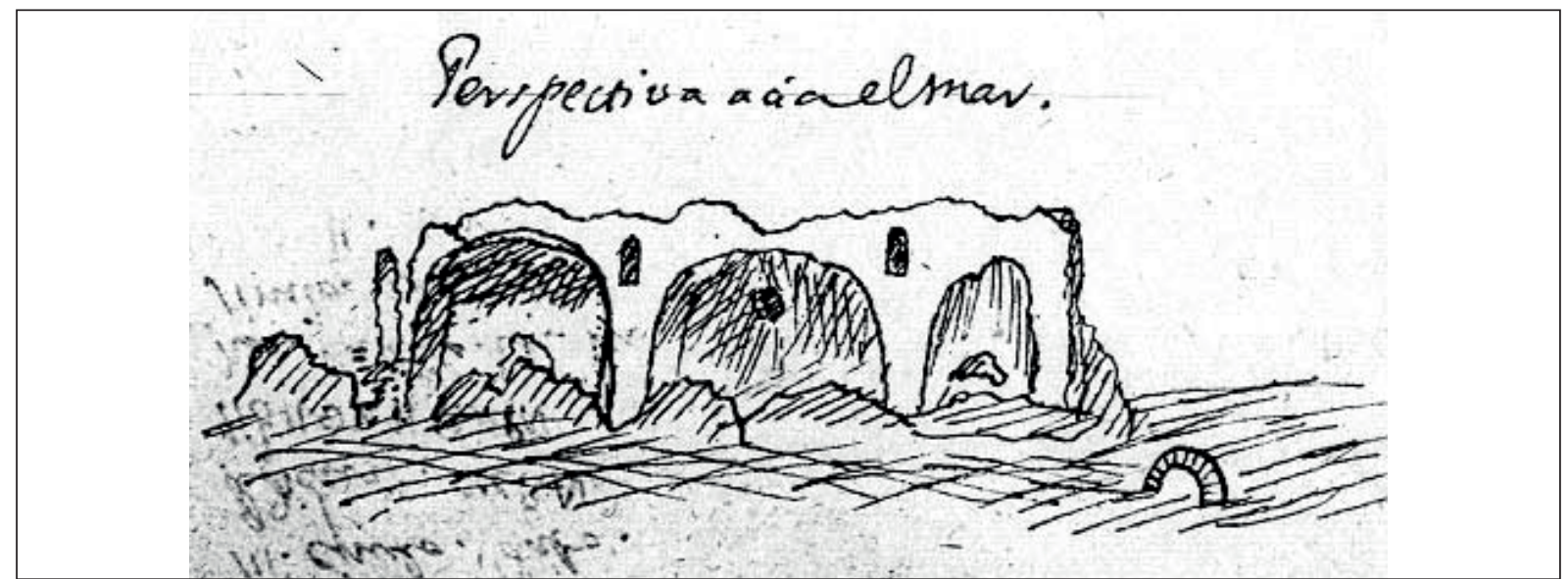

Figuras 11. Planta del monumento denominado Las Bóvedas (S. Pedro de Alcántara, Málaga), realizado por L.J. Velázquez. Archivo de la Real Academia de la Historia. Mss. 9-4128. 


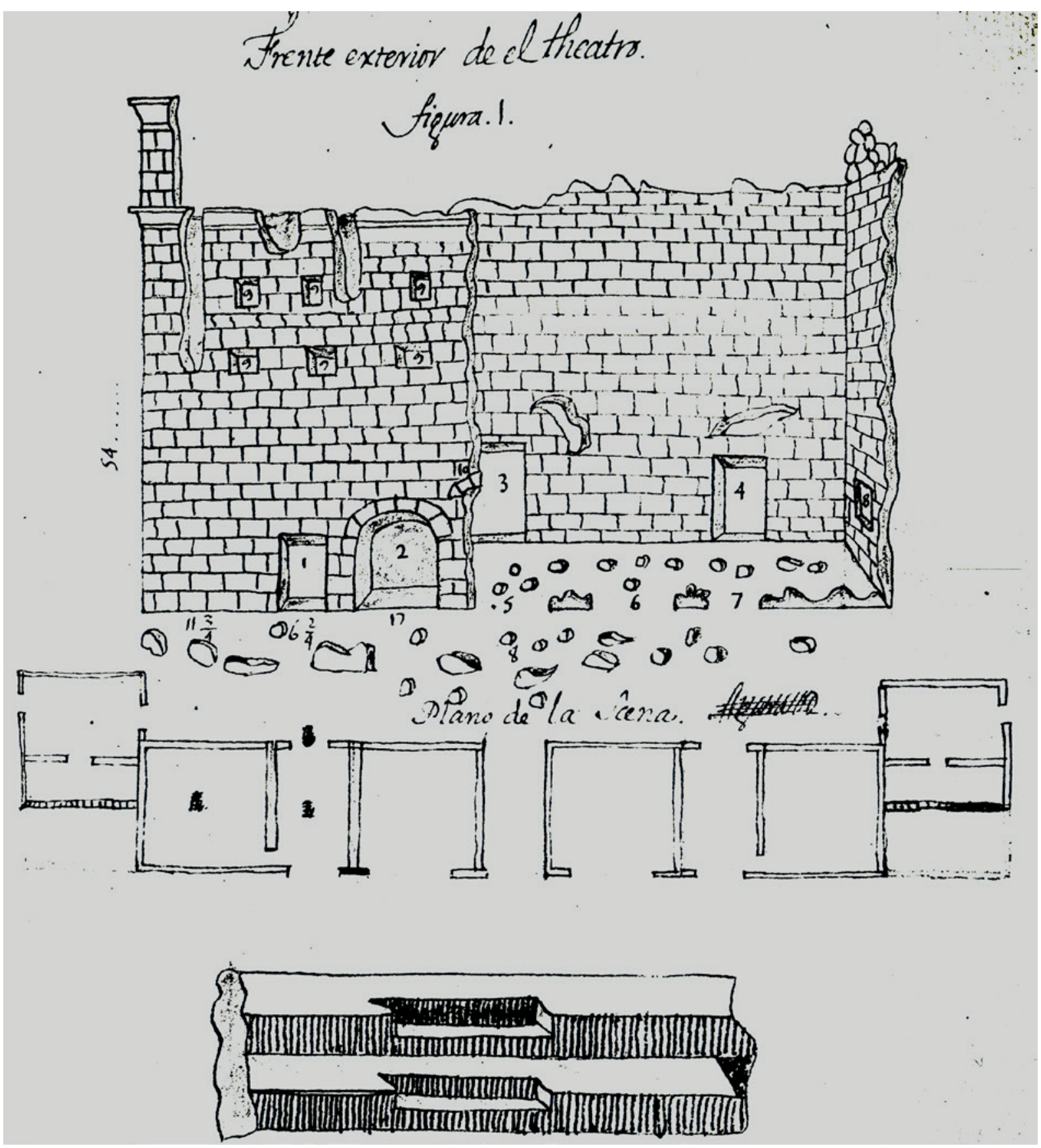

Figuras 12. Alzado y Planta de la Scena del Teatro de Acinippo. Archivo de la Real Academia de la Historia. Mss. 9-4128.

En el Despoblado de Ronda la Vieja describió las ruinas de la antigua Acinippo, donde se conservaba los restos de un teatro (Fig. 12), en el que todavía eran visibles "la maior parte de la scena, el proscenio y el semicírculo de las grada, el qual no está todo fabricado enteramente de piedras, sino cortada en la misma peña viva del monte, y por esto no tiene vomitorios esparcidos en medio de las gradas" (Velázquez s.a.c: 52; Velázquez 1750; Salas 2004: 663- 672; Manso 2010: 58; Salas 2010: 174-181).

También realizó descripciones de los restos conservados en otros yacimientos arqueológicos que visitó, como Carteia, la Torre Romana de Capión (Chipiona, Cádiz), las ruinas de Baelo Claudia, Cártama, Martos, el Templo 


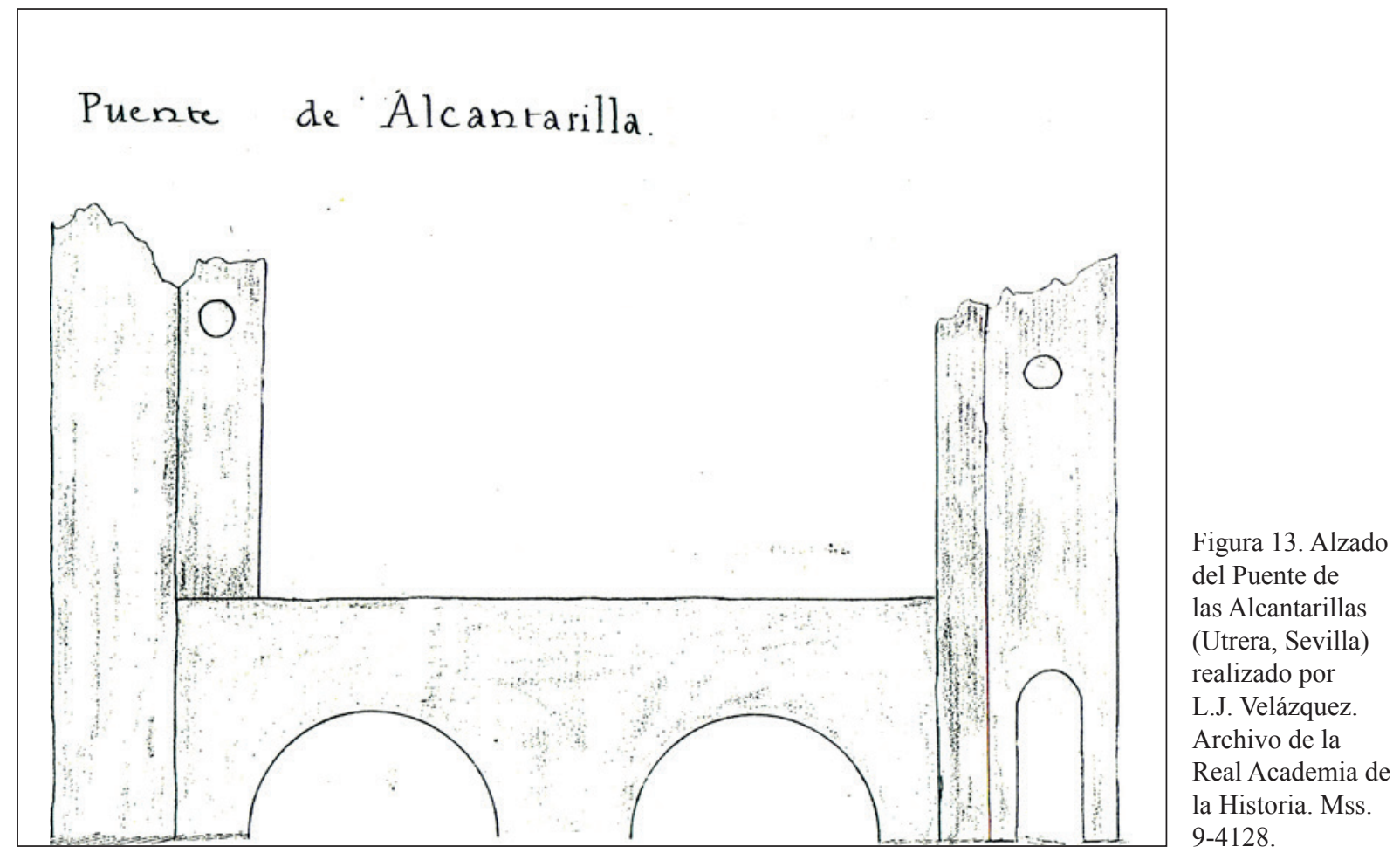

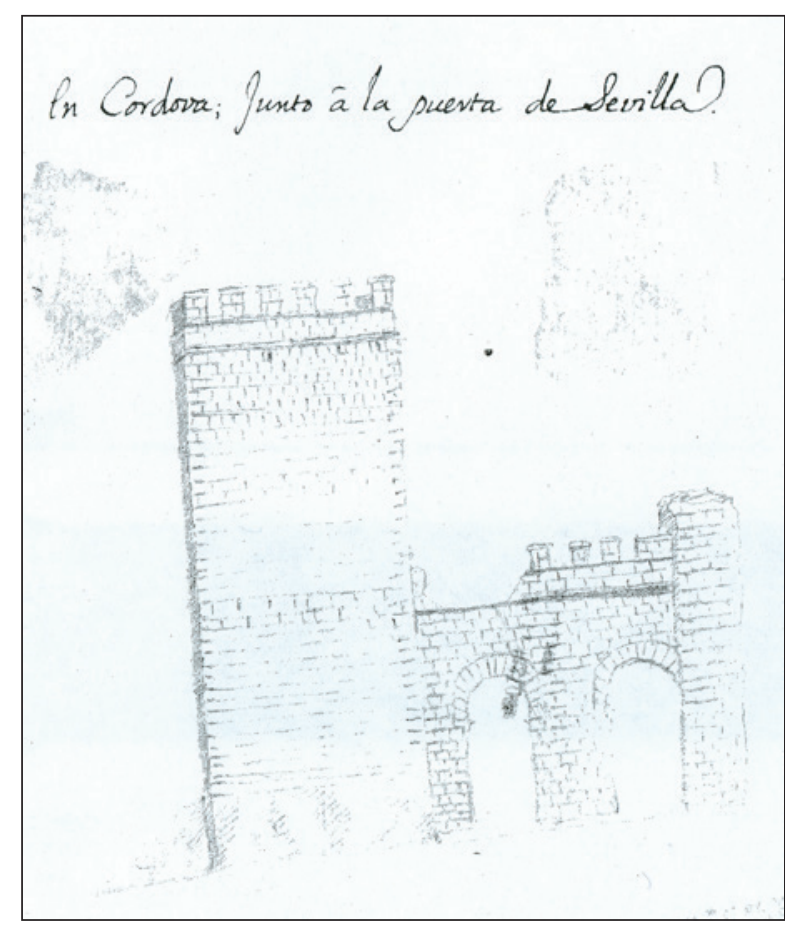

Figura 14. Alzado de la Puerta de Sevilla de Córdoba realizado por L.J. Velázquez. Archivo de la Real Academia de la Historia. Mss. 9-4128. de Marcelo de Córdoba, o el denominado Puente de las Alcantarillas (Fig. 13), situado en el Camino del Arrecife, que seguía el antiguo Iter à Gadibus Cordubam,.

Mostró un especial interés por el Anfiteatro de Itálica (Santiponce, Sevilla) "casi del todo destruido, y que por estarlo tanto, sería imposible ajustar su diseño a las verdaderas dimensiones, si ya antes no hubiese hecho este trabajo D. manuel Martí, de quien lo publicó el P. Montfaucon. Por las excavaciones ultimamente practicadas se han descubierto diez gradas sobre el podio, que no conoció Martí, por las cuales se determina el verdadero ambito de la arena" (Velázquez s.a.-c: $29 \mathrm{v}$ ).

Esta noticia de las excavaciones debe ser un error por parte de Velázquez, puesto que 1753 se realizaron excavaciones en el denominado Cerro de los Palacios (Flórez 1754: 224-225; Zevallos 1886: 26; León 1993: 38; Luzón 1999: 36-37; Luzón 2003: 52; Salas 2004: 612-613; Salas 2010: 138) y no en el Anfiteatro.

Quizás haga referencia a la visita efectuada al lugar en 1754 por Henrique Flórez, en compañía del Conde del Águila, Alcalde Ordinario de Sevilla, del dibujante Juan de Espinar y de Pedro de San Martín Lara, Arquitecto Mayor del Cabildo de Sevilla. En ese momento, y a instancias de Henrique Flórez, se levantaron diversos 


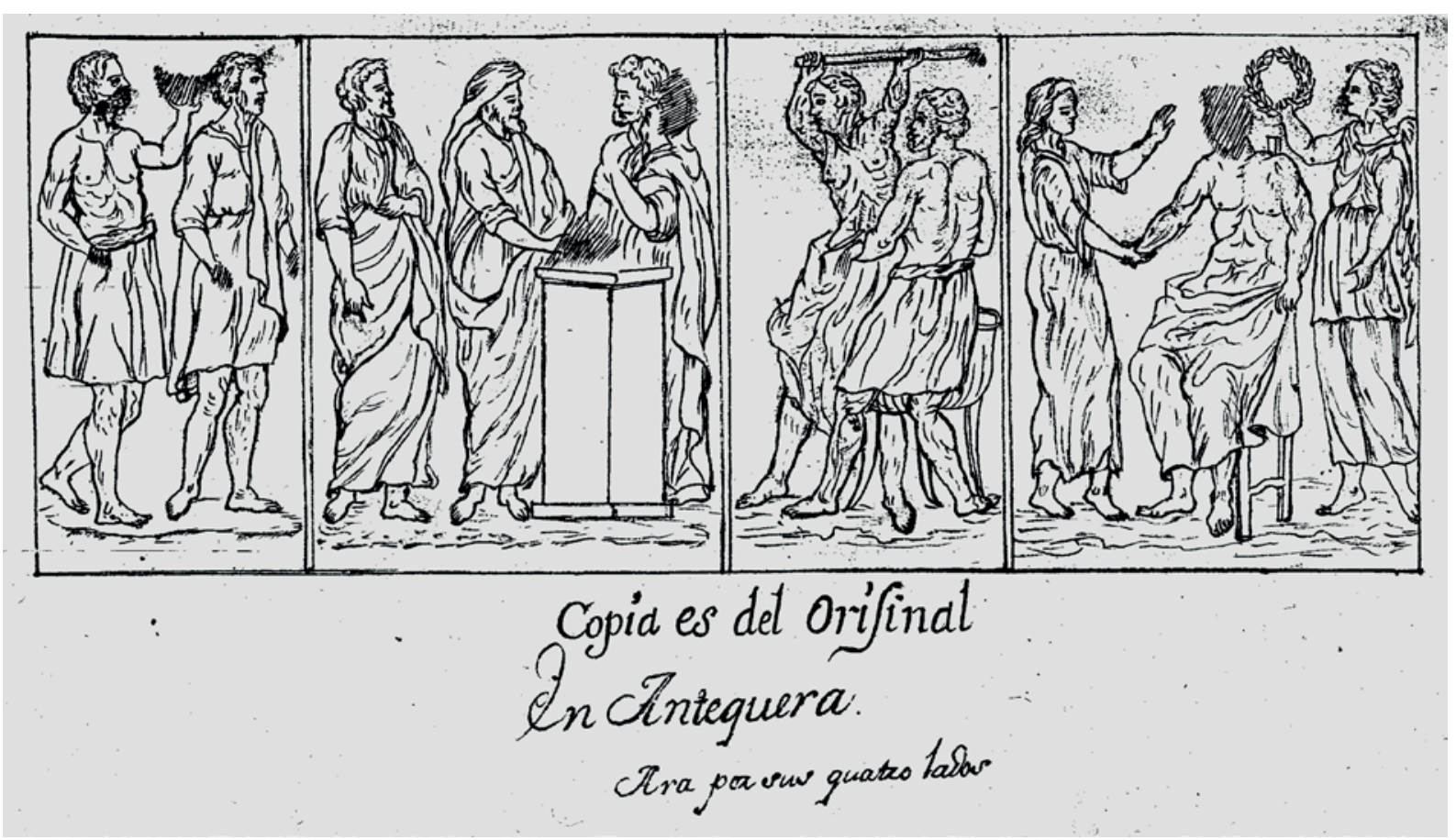

Figura 15. Dibujo del relieve situado en el Arco de los Gigantes de Antequera. Archivo de la Real Academia de la Historia. Mss. 9-4128.

planos del edificio, que acompañaron a una disertación $^{22}$ de Pedro San Martín (Flórez 1754: 227 y ss.; Salas 2004: 675-679; SALAS 2010: 184-188), que venía a completar los datos aportados por el Deán Martí.

A pesar de la importancia de su obra, no por ello está exenta de algunos errores, como por ejemplo su estudio sobre las murallas de Córdoba, que Velázquez consideró de época romana por su técnica constructiva a base de "piedras grandes y quadradas". En la denominada Puerta de Sevilla, existía una torre (Fig. 14) "quadrada, entera y bien conservada, que puede servir de modelo para distinguir en las demás partes del muro la obra antigua de la moderna. Está en el extremo de un lienzo de muralla sostenido de dos arcos, que sale del muro principal de la ciudad"--es decir una torre albarrana- "que servía para impedir que se acercasen a la puerta, y para defender los ángulo del muro".

Aunque esta edificación, según las últimas investigaciones, se dataría en época califal, sin embargo Velázquez consideró que "este lienzo de muralla nos da la idea de la fortificación exterior de Córdova en tiempos

22. Copia de esa disertación, titulada Noticias que yo Pedro de San Martín Lara, maestro mayor arquitecto del Ilmo. Cavildo Recinto de la ciudad de Sevilla, doy el Amphiteatro de Itálica, como se vé a el presente según el reconocimiento efectuado por orden de el Conde del Aguila. Sevilla 15 de Abril de 1754, se conserva en el Archivo de la Real Academia de la Historia, Mss. 9/ 7567 (I, 38). de los romanos. El arco más inmediato a la ciudad servía para dar paso a la gente que defendía el exterior del muro, y podía discurrir alrededor por la parte de afuera por cima de un terraplén levantado del suelo, $y$ defendido de un parapeto. El segundo arco era para que por él pasase el agua del foso, que estaba delante del parapeto, y le servia de defensa: y la torre colocada a la extremidad del lienzo servia para desde ella descubrir los demás ángulos de la ciudad y defenderlos" (Velázquez s.a.-c: 40v-41; Salas 2010: 48).

$\mathrm{Su}$ viaje también está repleto de descripciones de piezas singulares, de las que citaremos algunas. En Antequera, la Antikaria de las fuentes clásicas, visitó el denominado Arco de los Gigantes, del que transcribe las inscripciones allí encastradas, procedentes de la propia ciudad romana y de las poblaciones de Singilia Barba y Nescania, situadas en las cercanías.

Pero Velázquez llamó la atención sobre un relieve (Fig. 15) existente sobre el vano del arco, al que define como un "Ara antigua, con diferentes relieves, por todos quatro lados. En los tres representa un sacrificio, y en el otro hay una Victoria, coronando al emperador sentado, y dando la mano a una muger, que está en pie con tunica, y pelo suelto; la cual representa a alguna Provincia, por cuia pacificación, conseguida por medio de alguna Victoria son los sacrificios hechos a los Dioses, que se representan aqui"' (Velázquez s.a.-c: 29v). 
En Jerez de la Frontera (Cádiz) destacó la existencia de pedazo de una piedra que en Xerez está por umbral de la Puerta de una casa en la calle llamada de la Carne.

No se perciben puntos en ninguna letra, solo en los tres últimos renglones que parece son numeros tienen puntos. Las dos primeras letras de el Renglón tercero no se ven con sertesa si están unidas asi-y en una $M$, o si están divididas asi-que parecen dos NN. Es sensible que no se encuentre la otra mitad de esta inscripción (Fig. 16),

$$
\begin{gathered}
\text { dis maNIB } \\
\ldots . R N I \\
\ldots . M B \\
\ldots . \text { SMA } \\
\text { ter duLCIS } \\
\text { sima et deSI } \\
\text { deratisIMA } \\
\text { vix } \cdot \text { ann } \cdot L X \\
\text { mens } \cdot I I \cdot \\
s \cdot t \cdot t \cdot L \cdot
\end{gathered}
$$

Tiene esta parte de piedra poco menos de una baza de largo, y de ancho tiene por donde más una cuarta. Lo pintado es lo que se puede pensar que le falta"23 (Flórez 1751: 26-28; Salas 2004: 346).

En Medina Sidonia (Fig. 17) pudo ver su emplazamiento original, situado "en la Sacristía del Convento de Religiosos Franciscanos reformados, un sepulcro antiguo de mármol blanco. Por el lado de la frente está todo labrado con diferentes s de relieve entero, en que se ven los bustos de un hombre, y una muger dentro de un medallón sostenido de dos satiros, junto a los quales hai otros dos, y quatro Nimphas, y entre ellos algunos genios. Por la parte de abajo se ve el mar, y algunos Delphines, y Genios en ciertos barquillos" (Velázquez s.a.-c.: $32 \mathrm{v}$ ), y que posteriormente pasó a la colección particular del Marqués de la Cañada en El Puerto de Santa María (Recio 1974; Recio 1975; Buhigas y Pérez 1993; Beltrán 1999: 38-39 y 75-91; Rodríguez 2000; Beltrán 2008).

Asimismo, visitó las principales colecciones andaluzas de antigüedades. En Córdoba visitó la colección de Pedro Leonardo de Villacevallos, anotando y dibujando las principales inscripciones que se encontraban en ella (Fig. 18).

En Granada visitó el Gabinete de Pedro de la Cueva, oidor de la Real Chancillería, donde se encontraba "una estatua de Flora [y] otra de Venus, ambas de metal...,

23. Velázquez de Velasco, Luis José, Apuntes para un Corpus Inscriptionum Hispaniarum. ARAH. Mss.9/4155/2(13).

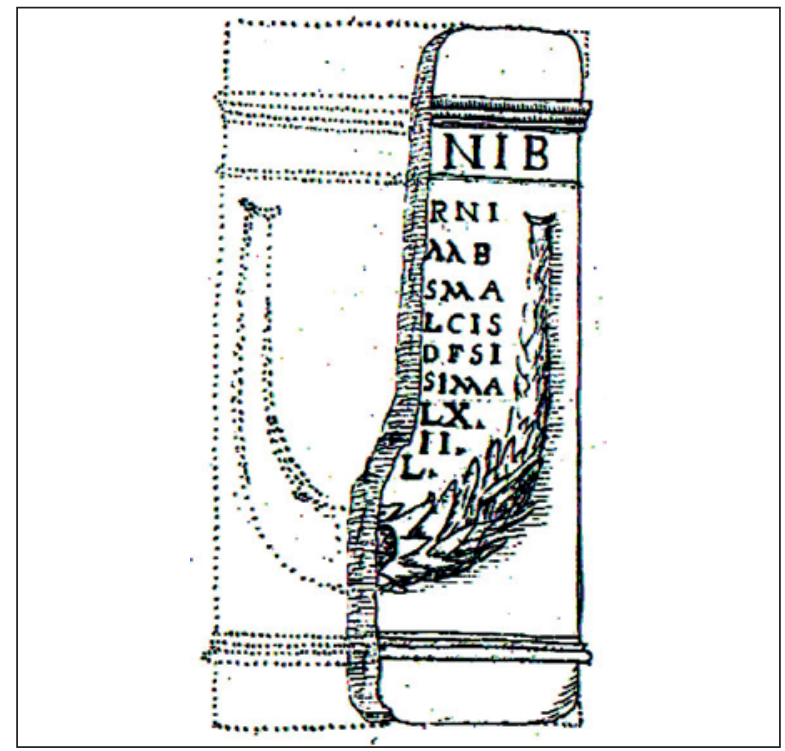

Figura 16. Dibujo del epígrafe CIL II 1311 según L.J. Velázquez. Archivo de la Real Academia de la Historia. Mss. 9-4128.

y una lámina de plomo con letras que yo no entiendo". También pudo visitar la colección de Juan de Flores, de la que destacó (Fig. 19) una "estatua de Ceres de piedra blanca con caractéres latinos y celtibéricos, y también un trozo de mármol blanco con una inscripción en letras celtibéricas" (Velázquez s.a.-c.: 25-26).

Durante su estancia en Sevilla, visitó la Colección del Duque de Alcalá, sita en la actual Casa de Pilatos, donde pudo contemplar "más de 200 piezas antiguas, y entre ellas muchas estatuas, bustos, y relieves, todos traídos de Roma. Entre ellas hay una tablas de mármol con bajos relieves, que representan dos combates navales, y dos triumphos, también hay una Ara, que según dicen los manuscritos de [Rodrigo] Caro, se encontró cerca de Guadix, de donde fue traída a Sevilla, y es la misma de que habla D. Manuel Marti’' (Velázquez s.a.-c.: 25-26) ${ }^{24}$.

Durante su estancia en la ciudad de Granada también conoció de primera mano las excavaciones que Juan de Flores acababa de comenzar en la Alcazaba: "luego que tuve noticia de los descubrimientos que se acababan de hacer en esta ciudad, pase a ella, reconocí el sitio y los monumentos que de él se habian sacado que se reducen a cinco inscripciones, no todas enteras, y un vaso de piedra, uno y otro de poquísima o ninguna

24. CIL II 3386. Los dibujos de Manuel Martí, fueron remitidos a Montfaucon, quien los publicó en el tomo IV, lámina CXLII de su obra Por oficio de fecha 08.06.1754 remitido por Velázquez a Montiano, ARAH CAG/9/7980/5 (50), hizo hincapié en conveniencia de que el monarca adquiriese esta pieza. 


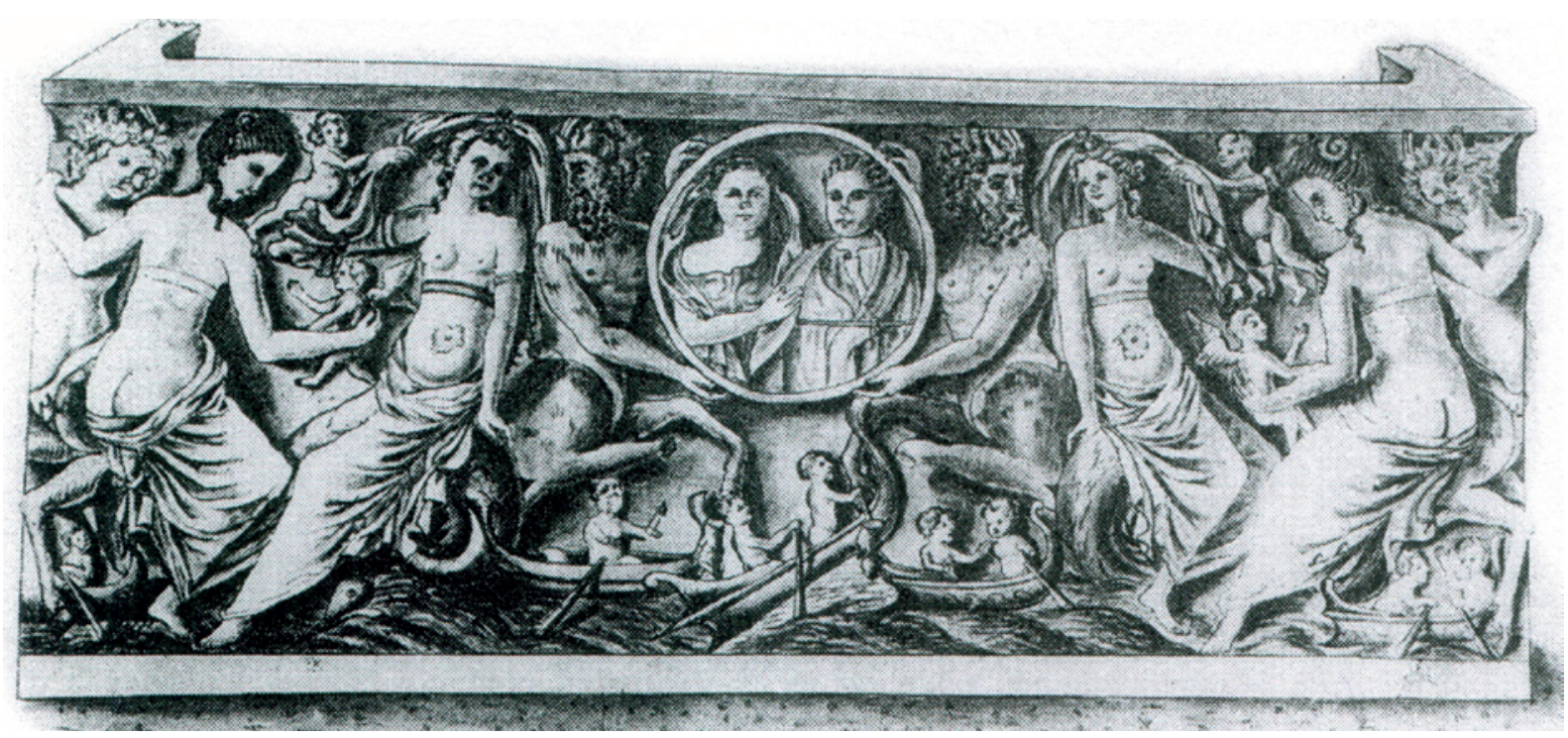

Figura 17. Dibujo del Sarcófago romano de Medina-Sidonia efectuado por Manuel de Ayora. Biblioteca Capitular y Colombina.

consecuencia no me determiné a seguir la excavación principiadas por el dueño del solar, por creer con bastante fundamento que allí no se descubriría cosa de provecho, y por que me arriesgaba a gastar el dinero de SM inutilmente y sin fruto como ha sucedido al descubridor, que conoce el fondo de la antigüedad, piensa que lo descubierto es gran cosa. Aquí sueñan que cavando se descubriran grandes edificios, pero como de las piedras descubiertas se infiera, que el sitio en que se encontraron era el Pomerium de la ciudad, no puedo yo persuadirme a ello, contando de un lugar de Livio que en el Pomerium jamás había edificio alguno, vuelvo a decir a V.I. Que este descubrimiento, que ha hecho tanto ruido en esta ciudad, no merece atención alguna"25.

Velázquez volvería a visitar las excavaciones en 1759, reiterando su oposición a los descubrimientos que plasmó en su inédito Discurso sobre los descubrimientos en el Sacromonte, Torre Turpiana y Alcazaba de Granada (Zamora 1989: 35; Álvarez 1996: 36).

Un hecho que marcó el futuro personal e investigador de Velázquez fue la destitución de su protector Zenón de Somodevilla, Marqués de la Ensenada, el 20 de Julio de 1754, como resultado de la lucha entre la facción anglófila y la francófona existente en el seno del gobierno de Fernando VI. A pesar de este contratiempo, consiguió terminar su viaje por Andalucía, que duró hasta fines de 1754.

25. Carta remitida el 17.03.1754 por Luis José Velázquez de Velasco a Agustín de Montiano y Luyando. ARAH. Mss. 9/6000, 129-130.

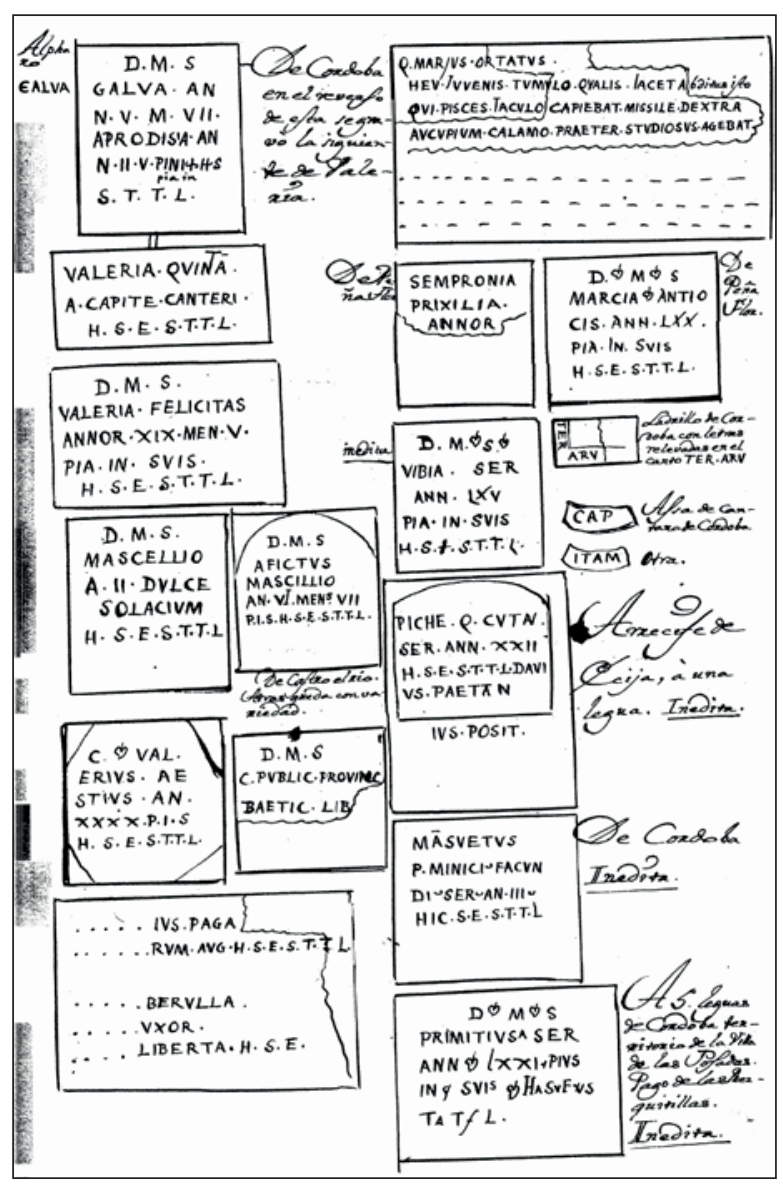

Figura 18. Dibujo realizado por L. J. Velázquez de algunas de las inscripciones del Lapidario reunido en Córdoba por Pedro Leonardo de Villacevallos. Archivo de la Real Academia de la Historia. Mss. 9-4128. 


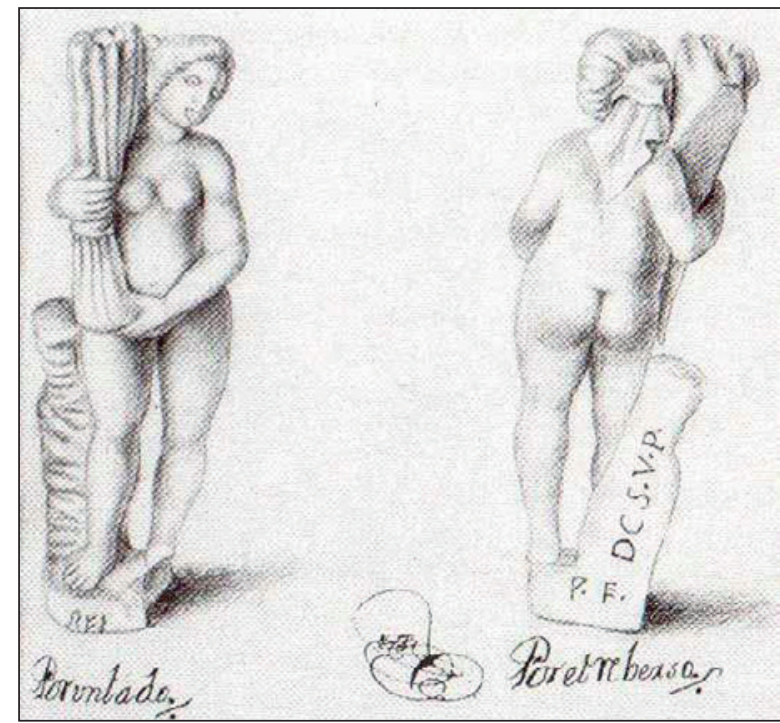

Figura 19. Dibujo de la escultura de Ceres existente en el Gabinete de Juan de Flores y Oddouz, realizado por L.J. Velázquez durante su visita a Granada en 1754. Archivo de la Real Academia de la Historia. Mss. 9-4128.

\section{TERCERA ETAPA: 1 DE ENERO DE 1755 A 1765}

A comienzos de 1755 Velázquez se retiró a Málaga, para coordinar sus trabajos y observaciones, de manera que a principios de 1755 pudo remitir a la Academia un primer tomo de su viaje ${ }^{26}$ que contenía las memorias sobre las Antigüedades de todos los lugares que había visitado (Huerta 1796: XXXVIII).

Mediante la Orden de 8 de Febrero de 1755, el Conde de Valparaíso, sustituto de Ensenada en la Secretaria de Estado, le comunicó a Veláquez la retirada de la pensión asociada a su proyecto ${ }^{27}$, pero éste era consciente de que estaba realizando "un trabajo que por su objeto merecía no ser suspendido", y "en vista de que el Rey no havía revocado el Decreto, en que me ordenó executar este viaje, ni por el presente se me ordenaba suspenderlo, y solo se mandaba suspender la pensión que para gastos se me había consignado, me resolvi a continuarle a mi costa, en la manera, $i$ hasta tanto que me fuese posible". Además, la Real Academia de la Historia decidió dar una continuidad al proyecto y sufragar a sus expensas el proyecto, con-

26. Oficio de fecha 14.01.1755 remitido por Luis José Velázquez de Velasco a Agustín de Montiano. ARAH. Mss. CAG/9/7980/5(55).

27. Oficio de fecha 08.02.1755 remitido por el Conde de Valparaíso a Agustín de Montiano y Luyando. ARAH. Mss. CAG/9/7980/5(57)

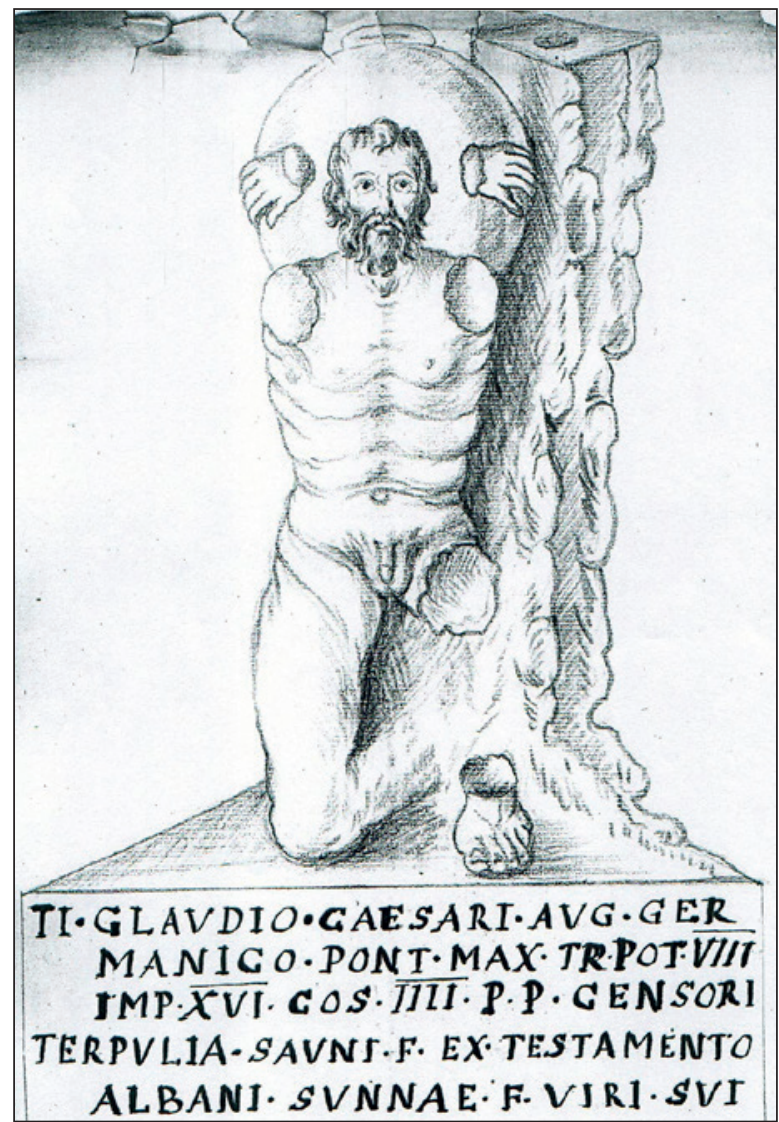

Figura 20. Vista de las ruinas de Munigua, según Tomás Andrés de Gusseme. Archivo de la Real Academia de la Historia. Mss. 9-4128.

traviniendo de esta manera las órdenes reales (Velasco 2000: 87$)^{28}$.

A pesar de esto, y de que contaba todavía con el apoyo de Agustín de Montiano y Luyando, los trabajos de Velázquez fueron cada vez más cuestionados en el seno de la Academia, donde los nuevos gobernantes, representados por Pedro Rodríguez de Campomanes, iban acaparando cada vez más poder.

Prueba de la falta de apoyo de la institución, fue la aprobación el 9 de Mayo de 1755 de la Representación del Sr. Don Pedro Campomanes a la Academia sobre la formación de una Colección de Inscripciones que reiteraba un proyecto inicialmente presentado en 1753 por el propio Campomanes, y que tenía por finalidad la realización de una "colección de inscripciones, epitafios y otros letreros de qualquier tiempo, carácter y lengua que se hallasen" (Huerta 1796: XLII; Salas 2004: 411435; Salas 2010: 61-79).

28. ASRAH 21.03.1755. 


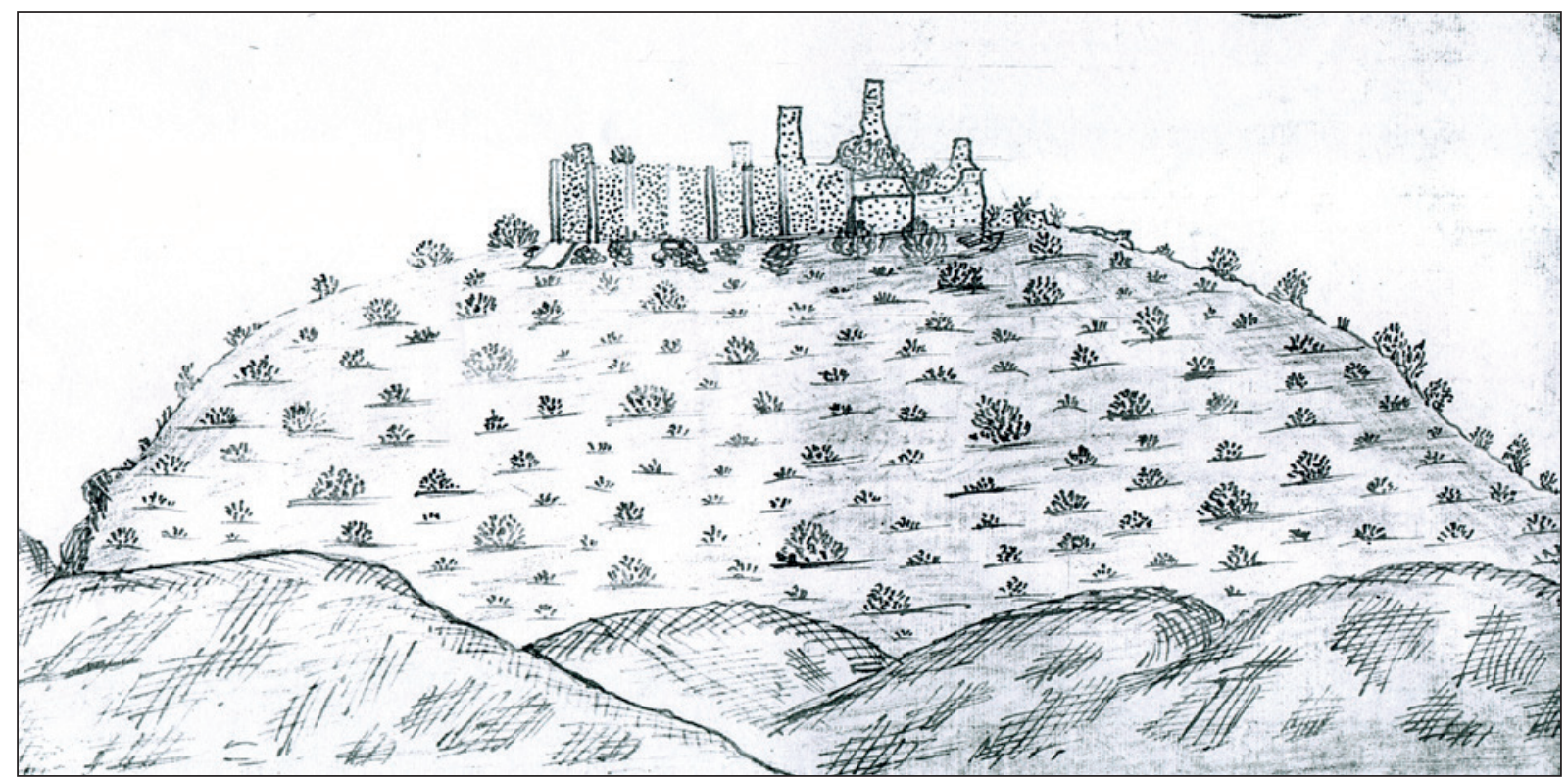

Figura 21. Dibujo efectuada por Tomás de Gusseme de la escultura de Atlas encontrada en Las Cabezas de San Juan (Sevilla). Archivo de la Real Academia de la Historia. Mss. 9-4128.

Pese a estas dificultades, Velázquez realizó todavía otros "cuatro viages por la Provincia de Andalucía, con el fin de continuar el de sus quatro reynos, que aun no había del todo viajado" (Velázquez 1765: $17-$ 18; Álvarez 1996: 34-35; Mora 2004: 40).

Asimismo, para completar su trabajo comenzó a recibir noticias de los informantes locales que conoció en su viaje o de algunos académicos de la Sevillana de Buenas Letras y de la Historia, en las que se contenían descripciones y dibujos de ruinas, como en el caso de Munigua (Fig. 20), o de pieza escultóricas destacadas, como el Atlas encontrada en 1762 en Las Cabezas de San Juan (Fig. 21), que habían sido remitidas inicialmente a la Academia de la Historia por Tomás Andrés de Gusseme.

De la documentación conservada en el archivo de la Real Academia de la Historia, sabemos que debió existir alguna relación entre el Padre Henrique Flórez y Luis José Velázquez de Velasco, puesto que son numerosos los epígrafes que vió Velázquez y que posteriormente pasaron a la obra del Padre Flórez ${ }^{29}$. Y al contrario ocurre lo mismo, puesto que muchos de los dibujos publicados por el Padre Flórez en su España Sagrada fueron utilizados por Velázquez en su obra

29. Flórez de Setién y Huidobro, Henrique (s.a.): Colecciones de Inscripciones, principalmente de Andalucia, copias para el uso de Fr. Enrique Flórez. RAH. Mss. 9/6118. manuscrita, como son los casos del Acueducto de Segovia, del Puente de Alcántara o de la Torre de Hércules de La Coruña.

Pero también aprovechó Velázquez para rastrear otras obras en busca de dibujos con los que completar sus observaciones. En este aspecto destaca la obra de Juan Vicente de Lastanosa, titulada Museo de las Medallas Desconocidas Españolas (Huesca 1645), de la que obtuvo algunos dibujos de ruinas de Caspe y de Chiprana (Fig. 22), con las que pretendía recopilar noticias para completar su obra.

Sin embargo, no pudo llevar a cabo sus intenciones, tal y como se aprecia en la falta del apoyo real inicialmente concedido, por lo que su Noticia de su Viaje de España (1765) no pasó de ser una mera declaración de intención de su proyecto, en la que únicamente se incluyeron los planteamientos teóricos y metodológicos del proyecto.

$\mathrm{Ni}$ siquiera puede hablarse de versión reducida o resumen, puesto que no se incluyó descripción alguna de los monumentos visitados o de los que tuvo conocimiento por otros autores. La gran novedad del proyecto de Velázquez de Velasco, que era el dibujo de los monumentos, ni siquiera fue atendida, ya que tanto los dibujos realizados por Esteban Rodríguez y por el propio Velázquez de Velasco como los procedentes de otras obras, quedaron inéditos entre los manuscritos de las obras de Velázquez, pasando desapercibidos para 


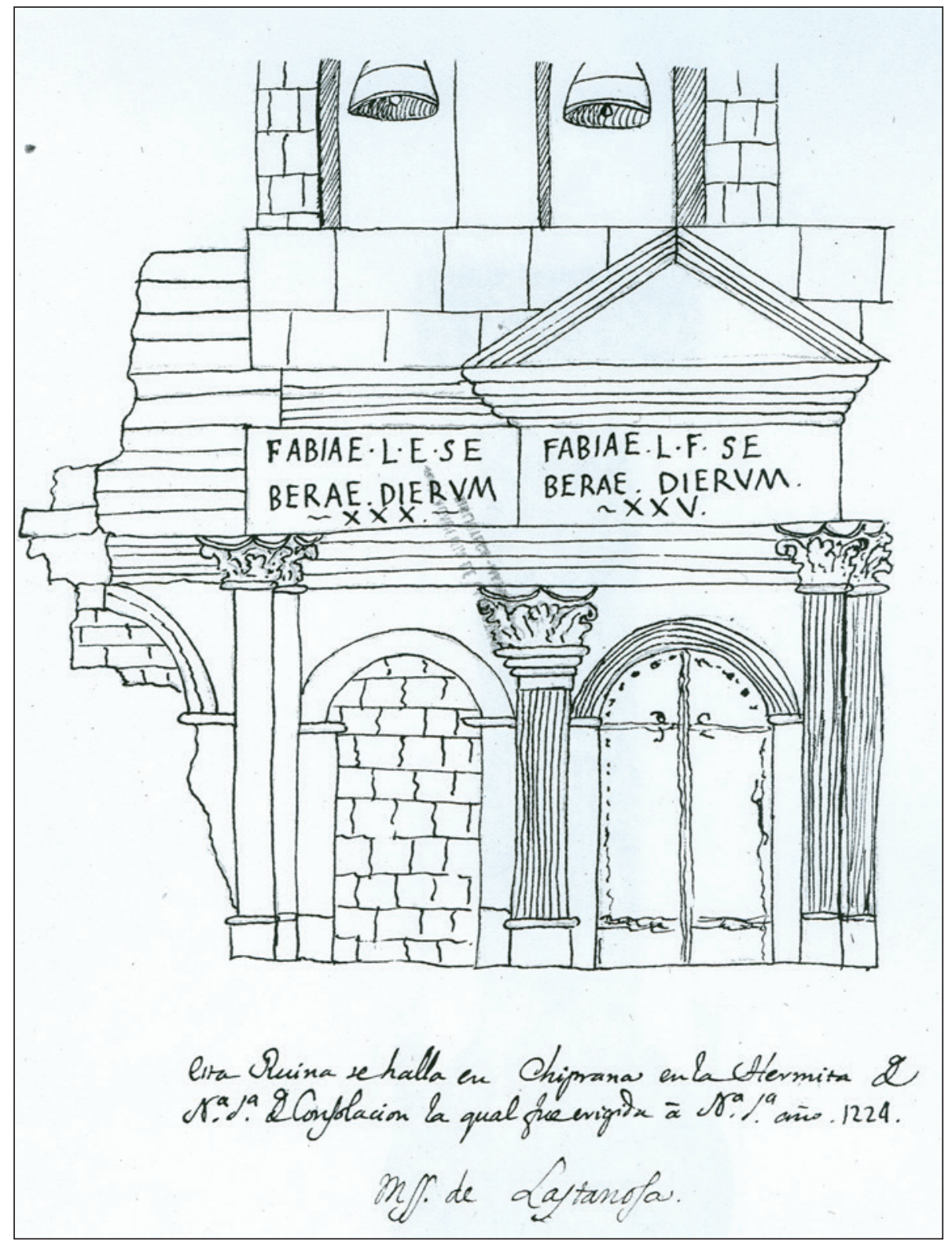

Figura 22. Dibujo de las ruinas de Chiprana efectuado por Juan Vicente de Lastanosa. Archivo de la Real Academia de la Historia. Mss. 9-4128.

la mayoría de los eruditos e investigadores españoles hasta fechas muy recientes.

A modo de conclusión, podemos decir que viaje de Luis José Velázquez de Velasco y Cruzado vino a representar en el ámbito civil, lo que el Patronato Regio y los viajes del Padre Burriel al ámbito religioso. Se trataba de una empresa estatal, a la que se le dotó de una precisa Instrucción, y en la que la Academia de la Historia fue la garante de su cumplimiento.

A pesar de las vicisitudes políticas que dieron al traste con el proyecto inicial, Velázquez consiguió terminar su trabajo, aunque gran parte del mismo quedase inédito hasta la actualidad, conformando el conjunto documental denominado Colección general de los antiguos documentos históricos de las cosas de España, compuesta de " 67 volúmenes, que contienen 13644 documentos, 439 escritores, 7008 diplomas, 4134 inscripciones, 2021 monedas, 62 monumentos de pintura (incluidos los mosaicos), escultura y arquitectura" ${ }^{30}$.

La pretensión fundamental era la obtención de documentos observados directamente del original, que

30. La colección abarca ARAH. Mss. 9/4095 a 9/4159 y los índices están en Mss. 9/4160. 
se materializó en la recopilación de una gran cantidad de documentación (epigrafes, monedas, monumentos, etc.) existentes in situ o en colecciones particulares o bien halladas en excavaciones arqueológicas contemporáneas. La intención de Velázquez era utilizar dichos materiales para realizar una colección general de todos los monumentos antiguos de España, que luego pudiera ser utilizada para los proyectos ilustrados de escribir una nueva Historia de España. En el caso concreto de las inscripciones tenia la finalidad de acabar con las transcripciones poco fiables y las falsificaciones de epígrafes, que tanto abundaban en las obras del momento.

Esta documentación fue utilizada por los diversos proyectos institucionales de la Academia de la Historia, pero el principal beneficiado fue E. Hübner, quien gracias a la documentación reunida pudo escribir en 1869 el volúmen II del Corpus Inscriptionum Latinarum, dedicado a Hispania.

También esta labor de Velázquez de Velasco fue propiciada gracia a la adopción de la Instrucción de 2 de noviembre de 1752 , la primera iniciativa tendente a la catalogación, protección y conservación del Patrimonio Arqueológico. En este cuerpo legal se especificaban claramente las obligaciones y atribuciones de los cargos políticos y administrativos, tanto de los ya existentes -corregidores y justicias- como de los creados bajo la dinastía borbónica -intendentes y superintendentes-.

Pero la labor de Velázquez de Velasco también es importante por otros aspectos:

- como en su día hizo el Deán Martí, atribuyó una gran importancia a las ruinas y vestigios arqueológicos, por ser elementos de primera mano para la explicación de la antigüedad de la nación.

- el uso de un lenguaje arquitectónico, con medidas y dimensiones, en la descripción de los monumentos antiguos, tal y como ya había hecho Velázquez con anterioridad en su descripción del Teatro romano de Acinipo (Velázquez 1750) o el Deán Martí en sus descripciones del Teatro de Sagunto (Martí 1705).

- fue la primera vez que se llevó a cabo la idea de dibujar los monumentos con la mayor precisión y exactitud posibles, ya que el dibujo se concibió como un catálogo o inventario de los monumentos antiguos, en donde se recogía la representación visual de los sistemas constructivos y compositivos del monumento, con los que elaboraron un álbum de anticuario, al que debía acompañarse una memoria explicativa de los mismos.
Este criterio de representación fue el adoptado para la conservación de las obras antiguas, sin que en ningún momento se pensase en la realización de obras de restauración. Es más, aunque se contemplaba la posibilidad de realizar pequeñas excavaciones arqueológicas, éstas no se pensaron como apoyo a una posible conservación, sino como instrumento para obtener "piezas arqueológicas" y sacar a la luz restos de estructuras arquitectónicas, que proporcionasen información para el estudio de la Historia Nacional.

En la obra de Velázquez también puede rastrearse cierta influencia de la obra de Piranesi, sobre todo en la manera de recopilar gráficamente los monumentos de la antigüedad. Piranesi pretendió realizar, a través de sus obras Vedute di Roma Antica e Moderna (Roma 1744) y Antichità romane de'Tempi della Repubblica e de'primi Imperatori disegnate e incise da Giambatttista Piranesi, architetto veneziano (Roma 1748), un compendio de la civilización romana desde sus principios hasta los últimos emperadores, analizando cada tipo de construcción, para lo cual la imagen y representación del monumento eran imprescindibles.

Otro precedente de este interés por la conservación de las antigüedades, y que podríamos citar como precedente del trabajo de Velázquez, sería la expedición organizada en 1751 por la londinense Sociedad de los Dilettanti, que envió a Atenas al pintor James Stuart (1713-1788) y al arquitecto Nicholas Revertt (17211804), con la tarea de anotar, medir y dibujar las antigüedades de Atenas y trazar un plano de la Acrópolis, que fue publicado bajo el título Antiquites of Athens mesured and delineated (Londres 1761-1762), y traducido al español en abril del mismo año por Felipe García Samaniego.

\section{BIBLIOGRAFÍA}

\section{Fuentes}

BARREIROS, Gaspar (1645): Antigüedades de Mérida. Mérida.

FLÓREZ DE SETIÉN Y HUIDOBRO, ENRIQUE (1754): España Sagrada. Teatro Geográfico histórico de la Iglesia de España. Origen, divisiones y límites de todas sus Provincias. Antigüedad, traslaciones y estado antiguo, y presente de sus Sillas en todos los dominios de España y Portugal. Con varias Disertaciones Críticas para ilustrar la Historia Eclesiástica de España. Tomo XII. Madrid. Oficina de Antonio Martín. 
GUTIÉRREZ, B. (1757): Historia del estado presente y antiguo de la Mui Noble y Muy Leal ciudad de Xerez de la Frontera. Colombina Mss. 84-3-15 y 843-16.

HUERTA, FRANCISCO MANUEL DE LA (1796): "Noticia del origen, progresos y trabajos literarios de la Real Academia de la Historia", Memorias de la Real Academia de la Historia I: I-CLXI.

LUXÁN, C. (1876): "Comunicaciones dirigidas al Marqués de la Ensenada dándole cuenta de las antigüedades e inscripciones halladas en la villa de Cártama", RABM VI: 210-214 y 223-226.

MAYANS I SISCAR, G.(1735): Emmanuelis Martini, Ecclesiae Alonensis Decani. Vita, scriptore Gregorio Maiansiano, generoso Valentino. Madrid.

MONTIANO Y LUYANDO, A. (1736): Proyecto de Historia de España. Geografía Sagrada y Profana. Madrid. RAH. Mss. 11/8035(3)

MORALES, A (1575): Las Antigüedades de las Ciudades de España que van nombradas en la Crónica con las averiguaciones de sus sitios y nombres antiguos. Alcalá de Henáres. (Reimpresión Imprenta Benito Calvo. Madrid 1792). BBCC. Mss. 107106-107.

VELÁZQUEZ DE VELASCO Y CRUZADO, L.J., Marqués de Valdeflores (1750): Disertación sobre el teatro y ruinas de Acinipo. RAH Mss. 9/5994 (fols. 125-162) y 11/8235(29).

- (1752a): Ensayo sobre los alphabetos de las lenguas desconocidas que se encuentran en las más antiguas medallas y monumentos de España. Madrid. Imprenta Antonio Sanz. BN Mss. 2-90140 y U-4904.

- (1752b): Instrucciones que le dio en 2 de Noviembre de 1752 el Marqués de la Ensenada y que debía observar en el viaje que debía emprender para averiguar y reconocer las antigüedades de España. RAH Mss. 9/6000.

- (1754): Cartas que escribió Don Luis José Velázquez de Velasco a la Real Academia de la Historia durante el tiempo que tuvo a su cargo la Comisión de la averiguación de las antigüedades de España. RAH Mss. 9/6000.

- (1765): Noticia del Viaje de España, hecho de orden del Rey. I de una nueva Historia General de la Nación desde el tiempo más remoto hasta el año 1516. Sacada únicamente de los escritores y monumentos originales, y contemporáneos. Con la Colección Universal de estos mismos escritores y monumentos recogidos. Madrid. Oficina de Don Gabriel Ramírez. BN Mss 5-4951 y RAH Mss. 9/7018.
- (s.a.-a): Epistolario de Velázquez con Montiano. BN Mss. 17546.

- (s.a.-b): Monumentos antiguos de Pintura, Escultura y Arquitectura. RAH Mss. 9/4128.

- (s.a.-c): Observaciones del viaje a Extremadura y Andalucía y noticia de algunos pasajes de escritores antiguos. RAH Mss. 9/4118.

ZEVALLOS Y MIER, FRAY FERNANDO (1886): La Itálica. BN Mss. R-14540

\section{Estudios}

ABASCAL PALAZON, J.M. y CEBRIÁN FERNÁNDEZ, R. (2005): Manuscritos de antigüedades de la Real Academia de la Historia. Madrid.

ALMAGRO GORBEA, M. (2002): "La Real Academia de la Historia y la arqueología española”, en Historiografía de la Arqueología Española: las instituciones. Madrid.

- (2003): Catálogo de Epigrafía Prerromana. Madrid. ALMAGRO GORBEA, M. y MAIER ALLENDE, J. (2003): "La Real Academia de la Historia y la Arqueología española en el Siglo XVIII", en Iluminismo e Ilustración. Le antichitá e i loro protagonisti in Spagna e in Italia nel XVIII secolo: 1-27. Roma.

ALVAREZ MARTÍ-AGUILAR, M. (1996): La Antigüedad en la Historiografia Española del Siglo XVIII: El Marqués de Valdeflores. Málaga.

- (2009): "Velázquez de Velasco, Luis Joseph", en M. Díaz-Andreu, G. Mora Rodríguez y J. Cortadella Morral (Coord.). Diccionario Histórico de la Arqueología en España (siglos XV-XX): 682-683.

- ÁLVAREZ MARTÍNEZ, J.M. (1972): "Las Termas Romanas de Alange", Habis 3: 267 ss.

---- (1973): “Alange y sus termas romanas", Revista de Estudios Extremeños 3: 445-494.

- (1976): "El Templo de Diana", Augusta Emerita. Actas del Simpoio Internacional conmemorativo del Bimilenario de Mérida: 43-53. Madrid.

- (1991): "El Templo de Diana", en Templos Romanos de Hispania (Cuadernos de Arqueología Romana 1): 83-93.

- (2010a): "Teatro de Emerita", en Corona y Arqueología en el Siglo de las Luces: 182-183. Madrid.

- (2010b): "Vista parcial del puente romano sobre el Guadiana en Mérida", en Corona y Arqueología en el Siglo de las Luces: 184-185. Madrid.

- (2010c): "Acueducto de los Milagros", en Corona y Arqueología en el Siglo de las Luces: 186-187. Madrid. 
AMORES CARREDANO, F.; BELTRAN FORTES, J. y FERNÁNDEZ LACOMBA, J (2008): El rescate de la antigüedad clásica en Andalucía. Sevilla.

ATENCIA PAEZ, R. (1981): "El arco de los Gigantes y la epigrafía antequerana". Jábega 35: 47-54.

BAENA DEL ALCÁZAR, L. (1997): "Noticias literarias sobre esculturas romanas desaparecidas", Baetica 19: 395-414.

- (1997): “A propósito de unos de los athloi de Hércules: las representaciones de Atlas en la Mauretania y en la Bética", Actas del II Congreso Internacional sobre El Estrecho de Gibraltar: 347 y ss. Madrid.

BELTRÁN FORTES, J. (1999): Los sarcófagos romanos de la Bética con decoración de tema pagano. Málaga.

- (2001): "La escultura clásica en el coleccionismo erudito de Andalucía (siglos XVII-XVIII)", en El Coleccionismo de Escultura Clásica en España: 143-172. Madrid.

- (2003a): "Las Esculturas", en J. Beltrán Fortes y J.R. López Rodríguez (ed.), El museo cordobés de Pedro Leonardo de Villacevallos. Coleccionismo arqueológico en la Andalucía del Siglo XVIII: 119148. Madrid-Málaga.

- (2003b): "La antigüedad romana como referente para la erudición española del siglo XVIII", en J. Beltrán Fortes, B. Cacciotti, X. Dupré and B. Palma Venetucci (eds.), Iluminismo e Ilustración. Le antichitá e i loro protagonisti in Spagna e in Italia nel XVIII secolo: 48-64. Roma.

- (2008a): "Sarcófago romano de Medina Sidonia", en F. Amores Carredano, J. Beltrán Fortes y J. Fernández Lacomba (eds.), El rescate de la antigüedad clásica en Andalucía. Sevilla, 202-205.

- (2008b): "Vistas de ruinas antiguas. Salduba (I-II)", en F. Amores Carredano, J. Beltrán Fortes y J. Fernández Lacomba (eds.), El rescate de la antigüedad clásica en Andalucía: 202-205. Sevilla.

BETHENCOURT MASSIEU, A. de (1963): "El Marqués de la Ensenada y la Arqueología: hallazgos romanos en las obras de cimentación del arsenal de Cartagena (1750-1752)", BSEAA XXIX: 73-87.

BUHIGAS, J.I. y PÉREZ, E. (1993): “El Marqués de la Cañada y su gabinete de Antigüedades del S. XVIII en el Puerto de Santa María", en J. Beltrán y F. Gascó (eds.), La Antigüedad como Argumento. Historiografía de Arqueología e Historia Antigua en Andalucía: 205-221. Sevilla.

CANTO DE GREGORIO, A. Ma (1994): “Un precursor del CIL en el Siglo XVIII: El Marqués de Valdeflores", BRAH CXCI (3): 499-516.
CARMONA BARRERA, J.D.(1999): Aquae. Análisis del desarrollo histórico-arquitectónico de Alange y sus baños romanos. Alange (Badajoz).

CEBRIÁN, R.; SALAMANQUÉS, V. y SÁNCHEZMEDINA, E. (2005): "La documentación sobre la Memoria del Viaje del Marqués de Valdeflores por España (Real Academia de la Historia, Ms. 9/7018)", Spal 14: 11-57. http://dx.doi.org/10.12795/ spal.2005.i14.01

GARCIA Y BELLIDO, A (1979): Arte Romano. Madrid. $2^{a}$ Edición.

GARCÍA Y BELLIDO, A. y MENÉNDEZ PIDAL, J. (1963): El dístilo sepulcral romano de Iulipa (Zalamea). Madrid.

GIMENO PASCUAL, H. y STYLOW, A (2003): "Las Inscripciones”, en J. Beltrán Fortes y J.R. López Rodríguez (eds.), El museo cordobés de Pedro Leonardo de Villacevallos. Coleccionismo arqueológico en la Andalucía del Siglo XVIII: 149-218. Madrid-Málaga.

GÓMEZ GÓMEZ, M. (1985): “Crítica Histórica y Archivos. El caso de España en el Siglo XVIII", Historia, Instituciones, Documentos 12: 199-231.

HÜBNER, E. (1869): Corpus Inscriptionum Latinarum II: Hispania. Berlín.

LAURENCIN, Marqués de (1926): Don Agustín de Montiano y Luyando primer Director de la Real Academia de la Historia. Madrid.

LEÓN GÓMEZ, A. (2006): Imágenes arqueológicas de la España Ilustrada. El Teatro romano de Sagunto en el siglo XVIII. Sevilla.

- (2007): El Estudio de los Edificios de Espectáculos Romanos en la España del Siglo XVIII. Análisis del Uso de la Imagen en los Inicios de la Arqueología Española. Tesis doctoral inédita. Universidad de Sevilla.

LUZÓN NOGUÉ, J.Ma. (1999): Sevilla la Vieja. Un paseo histórico por las ruinas de Itálica. Sevilla.

- (2003): "Las ruinas de Itálica y el convento de San Isidoro del Campo", en J. Beltrán Fortes y Mª Belén Deamos (eds.), El Clero y la Arqueología Española (II ${ }^{a}$ Reunión Andaluza de Historiografía Arqueológica): 49-62. Sevilla.

MAIER ALLENDE, J. (2002): Comisión de Antigüedades de la Real Academia de la Historia. Documentación General. Catálogo e Índices. Madrid.

- (2010): "Renovación e institucionalización de la investigación arqueológica en el reinado de Fernando VI (1746-1759), en Corona y Arqueología en el Siglo de las Luces: 147-157. Madrid.

MANSO PORTO, C. (2010): "Los dibujos de Esteban Rodríguez referentes al Viaje de las Antigüedades 
de España, del Marqués de Valdeflores (17521754)", Reales Sitios 186: 38-72.

MORA RODRÍGUEZ, G. (1996): "Literatura Anticuaria", en F. Aguilar Piñal (ed.), Historia Literaria de España en el Siglo XVIII: 883-914. Madrid.

- (1998): Historia de Mármol. La Arqueología Clásica Española en el Siglo XVIII. Madrid.

- (2003): "Luis José Velázquez de Velasco, Marqués de Valdeflores", Zona Arqueológica 3: Pioneros de la Arqueología Española (del siglo XVI a 1912): 39-41.

— (2009): "Viajes Literarios", en M. Díaz-Andreu, G. Mora Rodríguez y J. Cortadella Morral (coord.), Diccionario Histórico de la Arqueología en España (siglos $X V-X X)$ : 515-517.

- NAVARRO BONILLA, D. (2004): "Visitar archivos y anotarlo: la memoria de la investigación documental en el Siglo XVIII", Revista de Historiografia 1: 148-160.

NOGALES BASARRATE, T. y ÁLVAREZ MARTÍNEZ, J.Ma . (2003): Forum Coloniae Augustae Emeritae. El "Templo de Diana". Mérida.2 Vols.

RECIO DURAN, A.(1974): "El sarcófago romano de Medina Sidonia", BIEG 20: 91-107.

- (1975): "Sarcófago romano de Medina Sidonia", XIII CAN: 875 y ss.

RODRIGUEZ, R. (2000): "Recuperación de diversos fragmentos del desaparecido sarcófago romano de la Colección del Marqués de la Cañada", Revista de Historia de Jerez 6: 85-97.

RODRÍGUEZ OLIVA, P. (1979): "Esculturas del Conventus de Gades, III: las matronas sedentes de Cártama (Málaga)", Baetica 2: 131-148.

- (1980): "Investigaciones arqueológicas del Marqués de Valdeflores en Cártama (1751-1752)", Jábega 31: 41-46.
SALAS ÁLVAREZ, J. (2004): La recuperación del Patrimonio Arqueológico de Andalucía durante la Ilustración (1736-1808). Tesis Doctoral Inédita. Universidad de Sevilla.

- (2010): La Arqueología en Andalucía durante la Ilustración (1736-1808). Sevilla-Málaga.

SALAS ÁlVAREZ, J. y LEÓN GÓMEZ, A. (2005): "La Representación gráfica de la antigüedad clásica emeritense durante la Ilustración. El ejemplo del Teatro Romano", en V. Cabrera Valdés y M. Ayarzagüena Sanz (eds), El Nacimiento de la Prehistoria y de la Arqueología cientifica. Archaia 3-5: 86-103.

SÁNCHEZ MEDINA, E. y SALAMANQUES PÉREZ, V. (2008): "Un paysage de ruine à Mérida du XVIIIe. Siècle d'après L.J. Velázquez: monuments et inscriptions", en F. Baratte (dir.), L'Antiquité vue par les voyageurs : 123-136 La Rochelle (edición electrónica http://cths.fr/ed/ edition.php?id=4253)

SÁNCHEZ PALENCIA, Fco. J.; MONTALVO, A. y GIRONA, E (2001): "El Circo romana de Augusta Emerita", en El Circo en la Hispania Romana: 7595. Madrid.

SIMÓN DÍAZ, J. (1950): "El reconocimiento de los Archivos españoles en 1750-1756", Revista Bibliográfica y Documental IV: 131-170.

VELASCO MORENO, E. (2000): La Real Academia de la Historia en el Siglo XVIII: una institución de sociabilidad. Madrid.

THOUVENOT, R. (1940): Essai sur la province romaine de Bétique. Paris.

ZAMORA BERMÚDEZ, M. (1989): “Contribución del Marqués de Valdeflores a la Historia", Jábega 63: 31-40. 